\title{
OPEN Boosting carrier mobility and stability in indium-zinc-tin oxide thin-film transistors through controlled crystallization
}

\author{
Nuri On ${ }^{1}$, Bo Kyoung Kim ${ }^{1}$, Yerin Kim², Eun Hyun Kim ${ }^{3}$, Jun Hyung Lim ${ }^{3}$, Hideo Hosono ${ }^{4}$,
} Junghwan $\mathrm{Kim}^{4 凶}$, Hoichang Yang ${ }^{2 \bowtie}$ \& Jae Kyeong Jeong ${ }^{1 凶}$

We investigated the effect of film thickness (geometrical confinement) on the structural evolution of sputtered indium-zinc-tin oxide (IZTO) films as high mobility $\mathrm{n}$-channel semiconducting layers during post-treatment at different annealing temperatures ranging from 350 to $700{ }^{\circ} \mathrm{C}$. Different thicknesses result in IZTO films containing versatile phases, such as amorphous, low-, and highcrystalline structures even after annealing at $700^{\circ} \mathrm{C}$. A 19-nm-thick IZTO film clearly showed a phase transformation from initially amorphous to polycrystalline bixbyite structures, while the ultra-thin film $(5 \mathrm{~nm})$ still maintained an amorphous phase. Transistors including amorphous and low crystalline IZTO films fabricated at 350 and $700^{\circ} \mathrm{C}$ show reasonable carrier mobility $\left(\mu_{F E}\right)$ and on/off current ratio $\left(I_{\text {ON/OFF }}\right)$ values of $22.4-35.9 \mathrm{~cm}^{2} \mathrm{~V}^{-1} \mathrm{~s}^{-1}$ and $1.0-4.0 \times 10^{8}$, respectively. However, their device instabilities against positive/negative gate bias stresses (PBS/NBS) are unacceptable, originating from unsaturated bonding and disordered sites in the metal oxide films. In contrast, the 19-nm-thick annealed IZTO films included highly-crystalline, 2D spherulitic crystallites and fewer grain boundaries. These films show the highest $\mu_{F E}$ value of $39.2 \mathrm{~cm}^{2} \mathrm{~V}^{-1} \mathrm{~s}^{-1}$ in the transistor as well as an excellent $\mathrm{I}_{\mathrm{ON} / \mathrm{OFF}}$ value of $9.7 \times 10^{8}$. Simultaneously, the PBS/NBS stability of the resulting transistor is significantly improved under the same stress condition. This promising superior performance is attributed to the crystallization-induced lattice ordering, as determined by highly-crystalline structures and the associated formation of discrete donor levels $(\sim 0.31 \mathrm{eV})$ below the conduction band edge.

Amorphous indium gallium zinc oxide ( $a$-IGZO) has been used as a semiconducting channel material in activematrix thin-film transistors (TFTs) for high-resolution liquid crystal and large organic light-emitting displays (OLEDs) since its discovery by Hosono and co-workers in $2004^{1}$. Its attractive properties, such as high carrier mobility $\left(\mu_{F E}\right)$ of $>10 \mathrm{~cm}^{2} \mathrm{~V}^{-1} \mathrm{~s}^{-1}$, superior uniformity, ultra-low leakage current $(<1 \mathrm{pA})$, low temperature processing and low cost fabrication have facilitated rapid commercialization of pixel switchers and drivers in advanced display devices. The ever-increasing demand for larger screens, higher pixel resolution and higher frame rates for immersive and impressive image quality, however, have driven researchers to identify new routes to make much faster transistors. Thus, various semiconducting metal oxide materials such as indium zinc oxide (IZO), zinc tin oxide (ZTO), indium gallium tin oxide (IGTO) and indium zinc tin oxide (IZTO) have been investigated as alternatives of $\mathrm{IGZO}^{1-6}$. Among them, an amorphous IZTO $(a-\mathrm{IZTO})$ was identified to have a high $\mu_{F E}$ value of $\geq 30 \mathrm{~cm}^{2} \mathrm{~V}^{-1} \mathrm{~s}^{-1}$ in field-effect transistors (FETs). The synergic intercalation between the $5 \mathrm{~s}$ orbitals of $\mathrm{Sn}^{4+}$ and $\mathrm{In}^{3+}$ cations provides an efficient percolation conduction pathway, leading to low effective electron mass and enhanced carrier mobility in the resulting FETs ${ }^{7}$. However, the device stability is a critical factor in actual implementation and remains an issue because many gap states in the forbidden bandgap of $a$-IZTO are responsible for the bias-induced carrier trapping and the resulting threshold voltage $\left(V_{T H}\right)$ instability ${ }^{8,9}$.

Recently, the semiconducting oxides have been also researched as an alternative channel material for vertical NAND (V-NAND) flash memory devices ${ }^{10-14}$. The low mobility $\left(\leq 10 \mathrm{~cm}^{2} / \mathrm{Vs}\right)$ and non-negligible leakage current of polycrystalline Si thin-film transistors adopted in current V-NAND still limit the maximum number of

${ }^{1}$ Department of Electronic Engineering, Hanyang University, Seoul 133-791, Republic of Korea. ${ }^{2}$ Department of Chemical Engineering, Inha University, Incheon 22212, South Korea. ${ }^{3}$ R\&D Center, Samsung Display, Yongin 17113, South Korea. "Materials Research Center for Element Strategy, Tokyo Institute of Technology, Yokohama 226-8503, Japan. ${ }^{\circledR}$ email: JH.KIM@mces.titech.ac.jp; hcyang@inha.ac.kr; jkjeong1@hanyang.ac.kr 
vertically stackable layer. The high mobility $\left(\geq 30 \mathrm{~cm}^{2} \mathrm{~V}^{-1} \mathrm{~s}^{-1}\right)$ and excellent low leakage current of oxide FETs can mitigate these issues of polycrystalline $\mathrm{Si} F E T s$. Thus, the various charge trap stacks such as $\mathrm{SiO}_{2} / \mathrm{Si}_{3} \mathrm{~N}_{4} / \mathrm{SiO}_{2}$, $\mathrm{Al}_{2} \mathrm{O}_{3} / \mathrm{HfO}_{2} / \mathrm{Al}_{2} \mathrm{O}_{3}$ in conjunction with amorphous IGZO channel layer have been studied at a relatively low temperature $\left(\leq 400{ }^{\circ} \mathrm{C}\right)^{15-17}$. However, the high-temperature processability of IZTO channel layer in terms of structural and electrical properties has not been investigated yet even though the maximum process temperature of current V-NAND is larger than $700{ }^{\circ} \mathrm{C}$. Among the structural phases of semiconducting oxides, most of the research has focused on amorphous phases, which can provide the inherent benefits of uniform mobility and $V_{T H}$, leading to beneficial switching characteristics. However, amorphous relaxation causes many defects, such as bond length/angular disordering, unsaturated coordination, dangling bonds, etc. Bistability sites are responsible for severe threshold voltage $\left(V_{T H}\right)$ instability ${ }^{18-24}$. In this regard, polycrystalline oxide semiconductor-based transistors have been studied to achieve highly stable electronic devices. A single crystal-like $\mathrm{InGaO}_{3}(\mathrm{ZnO})_{5}(\mathrm{IGZO})$ layer yields a high $\mu_{F E}$ value of approximately $80 \mathrm{~cm}^{2} \mathrm{~V}^{-1} \mathrm{~s}^{-1}$ in the FET, but it can be formed at an extremely high annealing temperature of $1400^{\circ} \mathrm{C}$ for $30 \mathrm{~min}^{25}$. An as-deposited $a$-IGZO film is known to crystallize during annealing at 600 to $700^{\circ} \mathrm{C}^{26-29}$.

In our previous work, metal-induced crystallization reduced the initiation crystallization temperature of IGZO by up to about $300^{\circ} \mathrm{C}$, and the resulting crystalline IGZO layer showed an improved $\mu_{F E}$ value of $\sim 54$ $\mathrm{cm}^{2} \mathrm{~V}^{-1} \mathrm{~s}^{-1}$ in FET, 3 times greater than that of $a$-IGZO one $\mathrm{e}^{30}$. The result clearly suggests that the electrical properties of the semiconducting oxides were promoted by reducing the scattering of charge carriers in the semiconducting layer. However, in-depth understanding of the crystal grain and grain boundary (GB) distribution was still lacking because the top metal capping layer covered the structural form of the buried IGZO crystallites. During the crystallization, two- or three-dimensional $G B$ defects inevitably occurred, and they can act as charge traps or electrically inactive sites in the crystalline oxide semiconductor systems. It is known that the GB defects in Si-based FETs trap charges and form a Schottky barrier, which degrades the carrier mobility ${ }^{31-33}$. However, in metal oxide semiconductor systems, the $G B$-driven trap behavior is an interesting basic subject of material science and is important for potential industrial applications such as display, memory, logic and sensor devices, but it has not been systematically investigated.

Here, we investigated the evolution of microstructures in IZTO films of different thickness through hightemperature annealing at $700{ }^{\circ} \mathrm{C}$. By varying film thickness and annealing time, the structural phases in the annealed IZTO films changed from amorphous to partially crystallized to well crystallized microstructures. The topology and phase identification of the IZTO films were examined to understand how these microstructures affect the electrical performance of the resulting IZTO FETs. The reason for selecting high temperature annealing at $700{ }^{\circ} \mathrm{C}$ was that this temperature was enough to induce controllable crystallization from as-deposited $a$-IZTO films. For semiconductor devices on Si substrates such as DRAM, NAND and logic devices, this thermal budget is generally acceptable due to the high melting temperature (approximately $1410^{\circ} \mathrm{C}$ ) of silicon. An in-depth understanding of the lattice ordering, grain size, and $G B$ in the thickness-controlled IZTO phases could provide insight into the feasibility of polycrystalline oxide semiconductors for highly stable display backplanes and/or three-dimensional silicon-based electronics. An optimized 19-nm-thick IZTO film including a highly crystalline and less $G B$ structure showed a high $\mu_{F E}$ value of $39.2 \mathrm{~cm}^{2} \mathrm{~V}^{-1} \mathrm{~s}^{-1}$ in the transistor, as well as an excellent $I_{O N / O F F}$ value of $9.7 \times 10^{8}$. The positive/negative gate bias stress (PBS/NBS) stability of the resulting transistors was considerably improved under the same stress conditions. Our major finding was that the optimized polycrystalline IZTO FETs exhibited better electrical performance than the corresponding amorphous and partially crystallized IZTO FETs, suggesting that the lattice ordering and $G B$ minimization through intentional crystallization can be an alternative approach to make highly stable, high performance oxide backplanes or electronics.

\section{Results}

Optimal annealing of IZTO films. First, we investigated the effect of annealing temperature $\left(T_{A}\right)$ on the electrical properties of the IZTO films for high performance FETs. As-prepared IZTO films with a thickness of $19 \mathrm{~nm}$ were annealed at 350,600 , and $700^{\circ} \mathrm{C}$ for $1 \mathrm{~h}$, respectively. Electrical properties of these IZTO FETs were summarized in the Supporting Information (SI, see Figure S1 and Table S1). The $350{ }^{\circ} \mathrm{C}$-annealed IZTO FETs showed an average $\mu_{F E}$ value of $35.9 \mathrm{~cm}^{2} \mathrm{~V}^{-1} \mathrm{~s}^{-1}$, a $S S$ of $0.24 \mathrm{~V} \mathrm{decade}{ }^{-1}$ and a $V_{T H}$ of $-0.41 \mathrm{~V}$. However, a serious decrease in current modulation capacity (referred to as on and off current ratio, $I_{O N / O F F}$ ) was observed for the $600^{\circ} \mathrm{C}$-annealed IZTO FETs. This degradation is mainly attributed to the huge formation of oxygen vacancy $\left(V_{O}\right)$ defects with a donor character (see the $\mathrm{O} 1 \mathrm{~s}$ X-ray photoelectron spectra in Figure S2) where the high free carrier density $\left(>10^{19} \mathrm{~cm}^{-3}\right.$, determined from Hall effect measurement) in the $600{ }^{\circ} \mathrm{C}$-annealed IZTO film makes it difficult to deplete the resulting FET device under the negative gate voltage region ${ }^{34-37}$. Interestingly, the $700{ }^{\circ} \mathrm{C}$-annealed films exhibited optimized transfer characteristics: an average $\mu_{F E}$ value of $39.7 \mathrm{~cm}^{2} \mathrm{~V}^{-1} \mathrm{~s}^{-1}$, a $S S$ of $0.26 \mathrm{~V}$ decade ${ }^{-1}$, and a $V_{T H}$ of $-0.21 \mathrm{~V}$.

XRD patterns of the $19 \mathrm{~nm}$-thick IZTO films annealed at different $T_{A}$ s showed that IZTO films annealed even at $600{ }^{\circ} \mathrm{C}$ did not show any clear X-ray peaks, suggesting that the films were still amorphous phases. After annealing at either 650 or $700{ }^{\circ} \mathrm{C}$, the annealed IZTO films clearly showed X-ray diffraction peaks. Specifically, the $700{ }^{\circ} \mathrm{C}$ sample showed intense X-ray diffraction peaks, originating from crystal grains (Figure S3). This indicates that the IZTO films consisted of crystallites (this will be discussed later). The depth profiles of hydrogen for three IZTO films, which is known to be a shallow donor, were compared by TOF-SIMS analysis (see Figure S4 $)^{38-42}$. The IZTO films annealed at 600 and $700^{\circ}$ had the smaller hydrogen concentration than that $350{ }^{\circ} \mathrm{C}$, which suggests that the simple resistor-like behavior of $600^{\circ} \mathrm{C}$-annealed IZTO FETs cannot be explained by the hydrogen doping effect. Interestingly, crystallization due to minimization of thermodynamic Gibbs free energy during annealing at $700{ }^{\circ} \mathrm{C}$ should enhance the phase ordering and crystallinity in the resulting IZTO 
film, resulting in excellent electrical properties in FETs. It can be inferred that the reduction in $\mathrm{V}_{\mathrm{O}}$ concentration and high semiconducting functionality for the $700{ }^{\circ} \mathrm{C}$-annealed IZTO film would be related to its crystallization.

Phase transition of in-doped ZTO films: thickness and annealing time effects. It is known that the phase transition behavior of crystallizable metal oxide materials is significantly affected by film thickness (i.e., geometrical confinement) as well as annealing time and $T_{A}^{43-45}$. IZTO films of different thicknesses of 5, 10, 19,30 , and $50 \mathrm{~nm}$ were sputtered on $\mathrm{SiO}_{2}$ substrates and annealed at $700{ }^{\circ} \mathrm{C}$ for 1,2 or $4 \mathrm{~h}$. Figure 1 shows typical SEM morphologies of the $700{ }^{\circ} \mathrm{C}$-annealed IZTO films showing the structural evolution from particle-like, sheaf-like, to spherulitic grains as a function of the annealing time and thickness. The 5-nm-thick IZTO films showed only small nano-grains with diameters of 10-20 nm because crystallites were difficult to grow in a very confined geometry. As the film became thicker, the featured domains became interconnected and larger laterally. The partially-crystalline 10-nm-thick films showed embedded sheaf-like grains, and thicker films (above $10 \mathrm{~nm}$ ) contained 2D spherulitic crystallites interconnected with each other. Also, the longer annealing time seemed to increase the GB defects. As shown in Fig. 1, SEM morphologies of all the $4 \mathrm{~h}$-annealed samples showed much clearer physical gaps between these crystallites compared to those annealed for shorter times (also see Figure S5). The discernible structure variations in the $700{ }^{\circ} \mathrm{C}$-annealed IZTO films were expected to affect the electrical properties of the resulting FETs.

The $G B$ defect sites in the annealed IZTO films were further investigated using AFM. Figure 2 shows AFM topographies of IZTO films of different thickness on $\mathrm{SiO}_{2}$ substrates after annealing at $700{ }^{\circ} \mathrm{C}$ for 1 and $4 \mathrm{~h}$. As the film thickness increased, the AFM topographies showed typical particle-like, sheaf-like, and spherulitic grains. The morphological changes of the grains were similar to the trend observed in the SEM results. Nanoparticlelike grains in the 5 and 10-nm-thick films produced smooth film surfaces with a surface roughness (referred to as root mean square roughness, $R_{q}$ ) value of $0.25-0.34 \mathrm{~nm}$. Also, sheaf-like and spherulitic grains were grown in a $2 \mathrm{D}$ shaped structure rather than a $3 \mathrm{D}$ one due to the film thickness limitation. The resulting $R_{q}$ values varied from 0.24 to $0.38 \mathrm{~nm}$, depending on the grain morphologies. Interestingly, the 19-nm-thick IZTO film annealed for $1 \mathrm{~h}$ showed the lowest $R_{q}$ value of $0.24 \mathrm{~nm}$, suggesting that the $2 \mathrm{D}$ spherulites were well interconnected with less defects, suggesting that the charge transfer along these crystallites could be less degraded.

Figure 3 shows typical 1D GIXD profiles of IZTO films of different thickness annealed at $700{ }^{\circ} \mathrm{C}$ for 1 and $4 \mathrm{~h}$, respectively. First, the 5-nm-thick IZTO films did not show any X-ray diffraction peaks even after annealing at $700{ }^{\circ} \mathrm{C}$ for $4 \mathrm{~h}$. The amorphous nature of the 5 -nm-thick IZTO film was also confirmed by TEM analysis (see Figure S6). However, the relatively thicker films showed X-ray diffraction peaks in the $2 \theta$ range of $20-60^{\circ}$. The peak intensities tended to increase with an increase in $t_{s}$ and were less dependent on annealing time (Fig. 3a,b). The 10-nm-thick IZTO film showed weak X-ray diffraction peaks, expecting a less ordered and small crystal phase, while each X-ray diffraction peak was clearly indicated above $10 \mathrm{~nm}$. As shown in Fig. 3, typical X-ray profiles of these $700{ }^{\circ} \mathrm{C}$-annealed IZTO films showed diffraction peak series at $2 \theta=21.65,29.50,30.80,34.20$, $35.58,36.91,37.0$, and $51.10^{\circ}$, which would be indexed as those of typical ( $h k l$ ) crystal planes, respectively, in spinel $\mathrm{Zn}_{2} \mathrm{SnO}_{4}$ and cubic bixbyite $\mathrm{In}_{2} \mathrm{O}_{3}\left(\mathrm{c}-\mathrm{In}_{2} \mathrm{O}_{3}\right)$ phases (see Figure $\mathrm{S} 9$ and Table $\mathrm{S} 2$ in SI) ${ }^{36,46-49}$, suggesting that each $\mathrm{Zn}_{2} \mathrm{SnO}_{4}$ and $\mathrm{In}_{2} \mathrm{O}_{3}$ crystallite seemed to be simultaneously developed from the initially $a$-IZTO films during annealing at $700^{\circ} \mathrm{C}^{50-54}$. In addition, the existence of $\mathrm{SnO}_{2}$ crystallites in these films was found from synchrotron-based high resolution GIXD measurements performed for the IZTO films (Fig. 4).

Similar to the conventional GIXD results, the 5-nm-thick IZTO films did not show any X-ray diffraction peaks (except for the X-ray reflectivity profiles along the $Q_{z}$ axis) even after annealing at $700{ }^{\circ} \mathrm{C}$ for $4 \mathrm{~h}$. As shown in Fig. 4b,g, however, 2D GIXD patterns of the 10-nm-thick annealed films showed anisotropic (not isotropic or Debye) X-ray reflection peaks at $Q=1.540,2.060,2.372$, and $2.475 \AA$. The initial X-ray reflection peaks appeared to be sharper and more intensely separated as film thickness increased. Also, the 2D GIXD patterns of the 19-, 30 -, and 50-nm-thick IZTO films showed two additional peaks at 0.879 and $1.263 \AA$, as well as others at high $Q$ values of above $2.0 \AA$. As the film thickness increased, the resulting X-ray reflections were broadly scattered. Specifically, 2D GIXD patterns of the 50-nm-thick IZTO film showed Debye ring-like patterns (Fig. 4j). X-ray reflections for both the conventional and synchrotron-based measurements were found to be related to three crystalline phases including $\mathrm{SnO}_{2}, \mathrm{In}_{2} \mathrm{O}_{3}$, and $\mathrm{Zn}_{2} \mathrm{SnO}_{4}$ crystallites. Figure 5 represents $1 \mathrm{D}$ X-ray profiles extracted along the different tilting angle $(\theta)$ values of 0,45 , and $90^{\circ}$ with respect to the substrate for the $2 \mathrm{D}$ GIXD patterns of the 50 -nm-thick IZTO film annealed at $700{ }^{\circ} \mathrm{C}$ for $4 \mathrm{~h}$. The data indicate that the polycrystalline structure is not random but has a certain degree of preferential orientation.

Figure 6 shows the cross-sectional TEM morphologies, electron diffraction (ED) patterns, and element mapping images of the 10,19, and 50-nm-thick IZTO films after annealing at $700{ }^{\circ} \mathrm{C}$ for $1 \mathrm{~h}$. First, it was found that the 10 -nm-thick film was partially crystalline as determined by the diffused ED ring pattern in a sectioned film area (see Figure S11). However, the crystal regions clearly showed aligned planes with a domain-spacing ( $d$-spacing) of about $2.90 \AA$, corresponding to that of $d_{222}$ in a bixbyite $\operatorname{In}_{2} \mathrm{O}_{3}$ crystallite. In contrast, the 19-nmthick IZTO film contained fully-occupied crystallites, where highly-ordered crystal planes also had a $d$-spacing of $2.90 \AA$, which was attributed to $d_{222}$ in a bixbyite $\operatorname{In}_{2} \mathrm{O}_{3}$ crystallite. Lattice images assignable to the spinel $\mathrm{Zn}_{2} \mathrm{SnO}_{4}$ crystallite were observed in other regions of 19 -nm-thick IZTO films (data shown in Figure S12). TEM morphologies revealed additional crystal structures with $d$-spacings of $2.60 \AA$, which can be indexed as (311) of $\mathrm{Zn}_{2} \mathrm{SnO}_{4}$ crystallites. The scanning TEM analysis clearly shows the dispersive distribution of In, $\mathrm{Zn}$, and $\mathrm{Sn}$ cations without discernible separation features. This is rather unexpected because the co-existence of three phases of $\mathrm{SnO}_{2}, \mathrm{In}_{2} \mathrm{O}_{3}$ and $\mathrm{Zn}_{2} \mathrm{Sn}_{1} \mathrm{O}_{4}$ with finite crystalline size should result in spatial non-uniformity in terms of In, $\mathrm{Zn}$ and $\mathrm{Sn}$ cations. This indicates that the chemical formula of the thermodynamically stable bixbyite and spinel phase at high temperature would be $\mathrm{In}_{(2-2 \mathrm{x})} \mathrm{Zn}_{\mathrm{x}} \mathrm{Sn}_{\mathrm{x}} \mathrm{O}_{3}$ and $\mathrm{Zn}_{(2-\mathrm{y})} \mathrm{Sn}_{(1-\mathrm{y})} \mathrm{In}_{2 \mathrm{y}} \mathrm{O}_{4}$ rather than pure $\operatorname{In}_{2} \mathrm{O}_{3}$ and $\mathrm{Zn}_{2} \mathrm{SnO}_{4}$, respectively, which is known to be a sub-solid phase relationship in the $\mathrm{InO}_{1.5}-\mathrm{ZnO}-\mathrm{SnO}_{2}$ system ${ }^{50}$. 


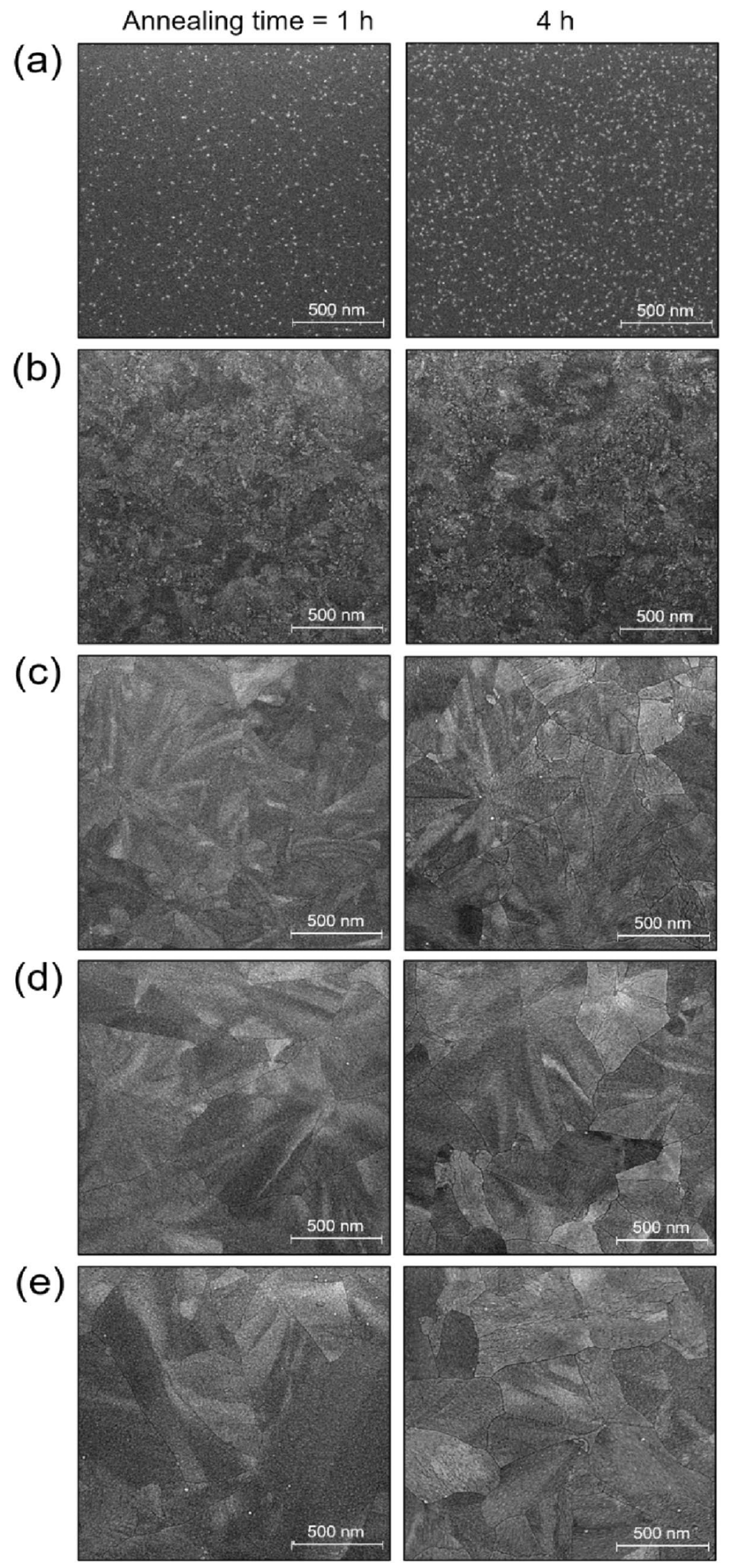

Figure 1. SEM morphologies of IZTO films of different thickness after annealing at $700{ }^{\circ} \mathrm{C}$ for 1 and $4 \mathrm{~h}$ : (a) 5, (b) 10, (c) 19, (d) 30, and (e) $50 \mathrm{~nm}$. 

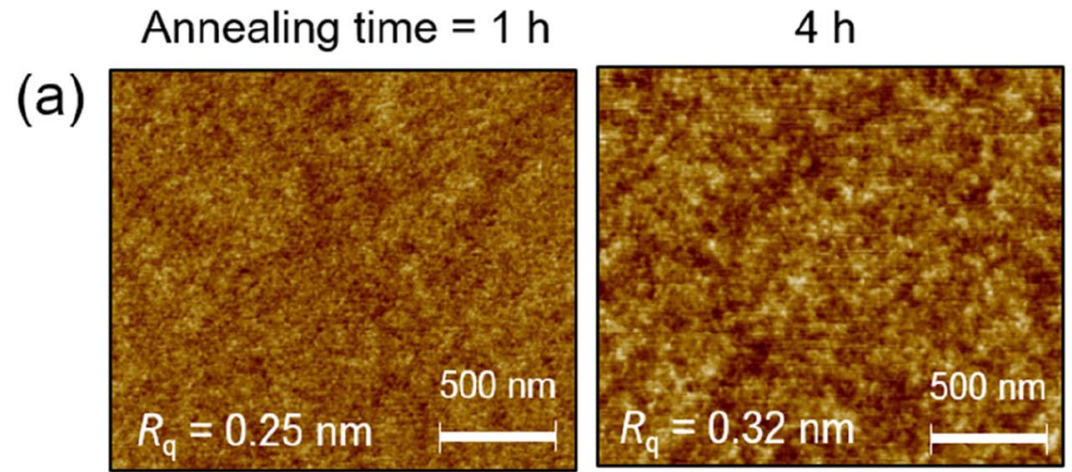

(b)
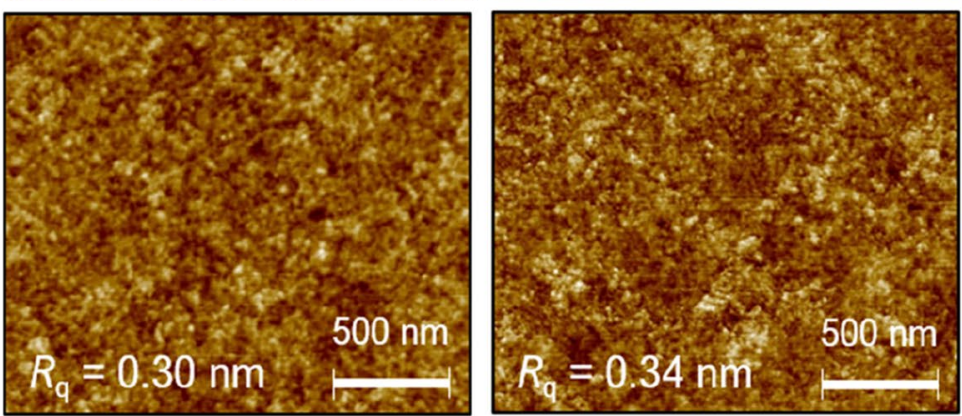

(c)
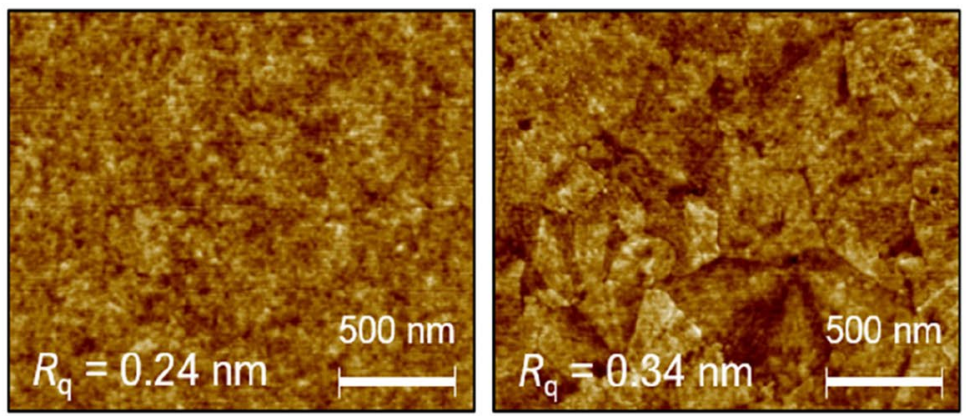

(d)
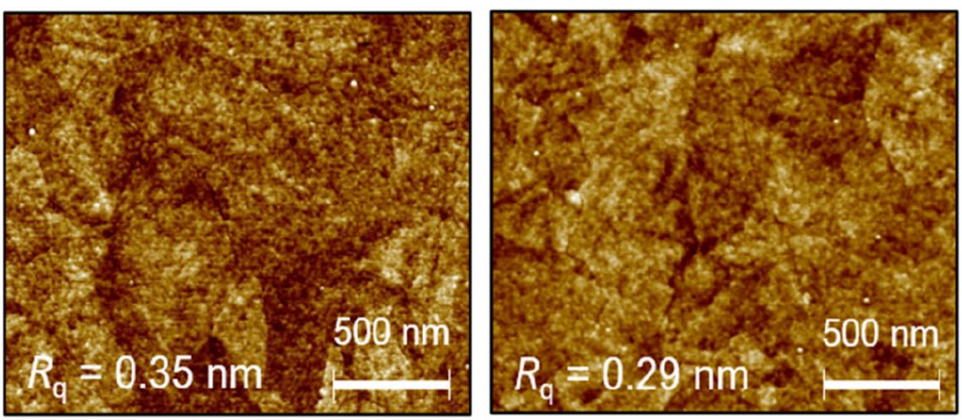

(e)

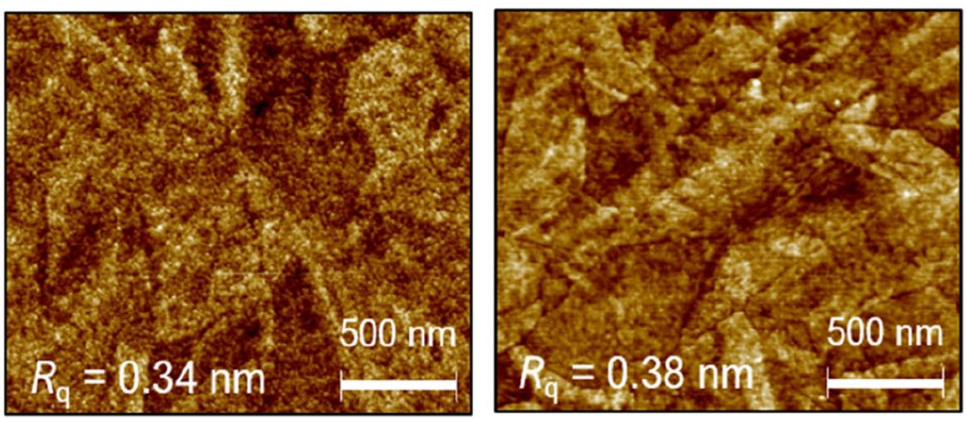

Figure 2. AFM topographies of IZTO films of different thickness after annealing at $700{ }^{\circ} \mathrm{C}$ for 1 and 4 h: (a) 5 , (b) 10, (c) 19, (d) 30, and (e) $50 \mathrm{~nm}$. AFM topographies for the IZTO films annealed at $700{ }^{\circ} \mathrm{C}$ for $2 \mathrm{~h}$ is shown in Figure $\mathrm{S} 7$. 

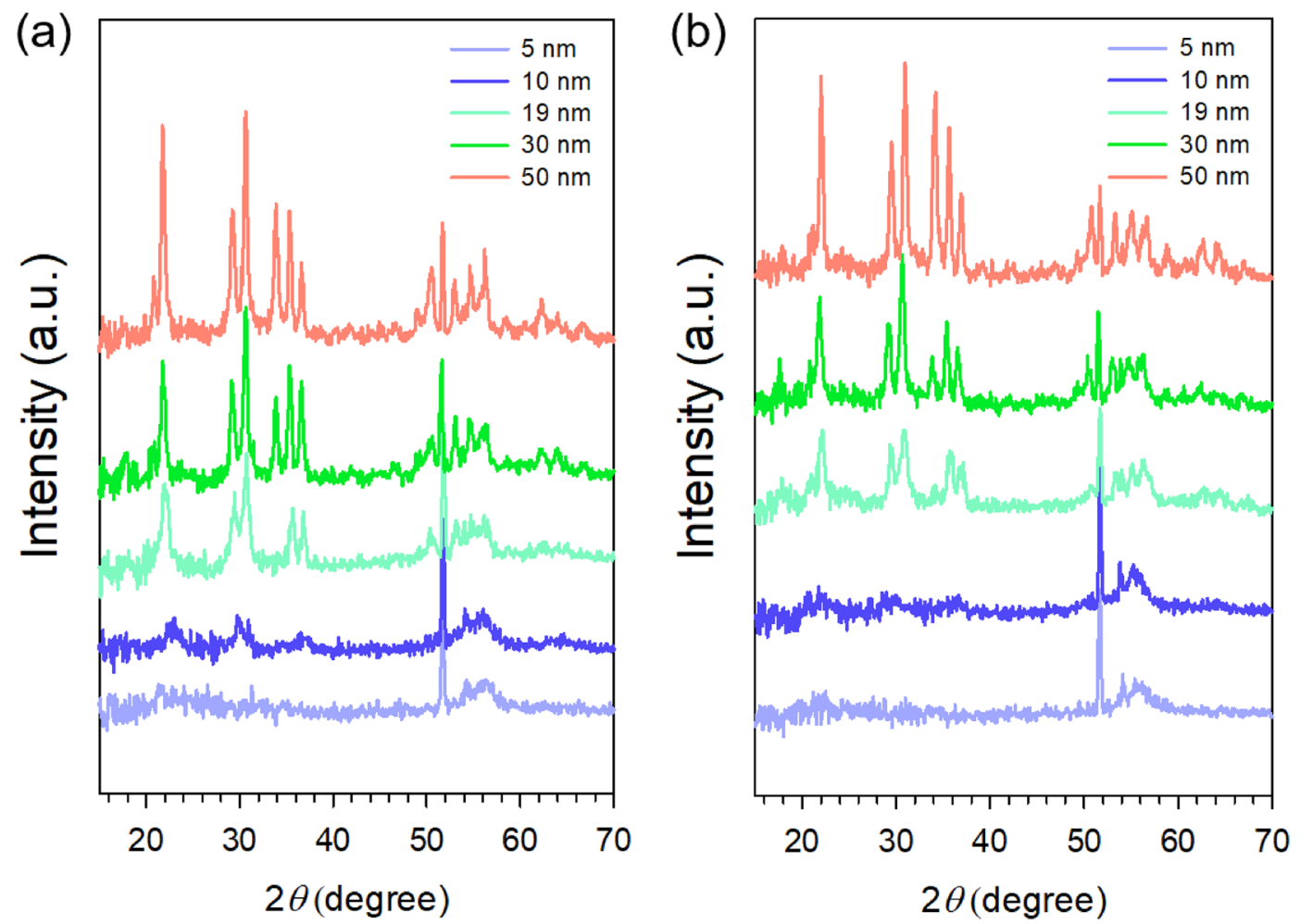

Figure 3. 1D X-ray diffraction patterns of IZTO films of different thickness annealed at $700{ }^{\circ} \mathrm{C}$ for (a) 1 and (b) $4 \mathrm{~h}$ (the wavelength of X-ray was $1.54056 \AA$ ). The $1 \mathrm{D}$ X-ray diffraction pattern for the IZTO films at $700{ }^{\circ} \mathrm{C}$ for $2 \mathrm{~h}$ is shown in Figure S8.
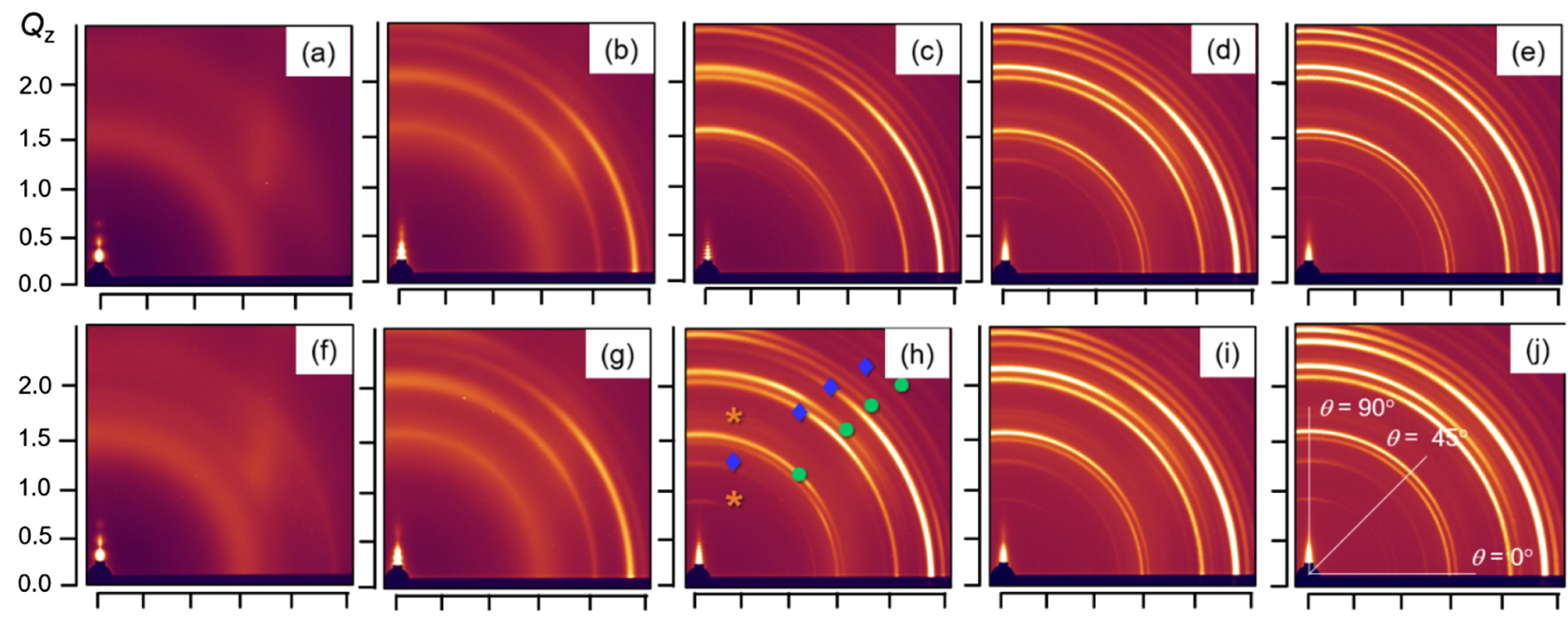

$0.00 .5 \quad 1.0 \quad 1.5 \quad 2.0$

$\begin{array}{llllll}0.0 & 0.5 & 1.0 & 1.5 & 2.0 & 2.5\end{array}$

$Q_{r}\left(\AA^{-1}\right)$

Figure 4. 2D GIXD patterns of IZTO films of different thickness after annealing at $700{ }^{\circ} \mathrm{C}$ for $(\mathbf{a}-\mathbf{e}) 1$ and $(\mathbf{f}-\mathbf{j})$ $4 \mathrm{~h} ;(\mathbf{a}, \mathbf{f}) 5,(\mathbf{b}, \mathbf{g}) 10,(\mathbf{c}, \mathbf{h}) 19,(\mathbf{d}, \mathbf{i}) 30,(\mathbf{e}, \mathbf{j}) 50 \mathrm{~nm}$ (the orange-, blue-, and green-colored symbol-marked peaks in $\mathrm{h}$ represent typical peaks of $\mathrm{SnO}_{2}, \mathrm{Zn}_{2} \mathrm{SnO}_{4}$, and $\mathrm{In}_{2} \mathrm{O}_{3}$, respectively). 2D GIXD patterns of IZTO films of different thickness after annealing at $700{ }^{\circ} \mathrm{C}$ for $2 \mathrm{~h}$ are also shown in Figure S10.

According to the ternary phase diagram of $\mathrm{InO}_{1.5}-\mathrm{ZnO}-\mathrm{SnO}_{2}$ determined at $1,250^{\circ} \mathrm{C}$, the specific composition $\mathrm{In}_{0.23} \mathrm{Zn}_{0.37} \mathrm{Sn}_{0.40} \mathrm{O}$ used in this study has the three equilibrium phases including $\mathrm{SnO}_{2}$, a bixbyite solid solution $\mathrm{In}_{(2-2 \mathrm{x})} \mathrm{Zn}_{\mathrm{x}} \mathrm{Sn}_{\mathrm{x}} \mathrm{O}_{3}(\mathrm{x} \approx 0.4)$ and a spinel solid solution $\mathrm{Zn}_{(2-\mathrm{y})} \mathrm{Sn}_{(1-\mathrm{y})} \mathrm{In}_{2 \mathrm{y}} \mathrm{O}_{4}(\mathrm{y} \approx 0.2)^{50}$. The extended co-solubility of $\mathrm{Zn}$ and $\mathrm{Sn}$ in the bixbyite $\mathrm{In}_{2} \mathrm{O}_{3}$ phase is rationalized based on the good size-matching and isovalent nature of the substitution, where two trivalent In cations $\left(\mathrm{In}^{3+}\right)$ are substituted by one divalent $\mathrm{Zn}^{2+}$ and one tetravalent 


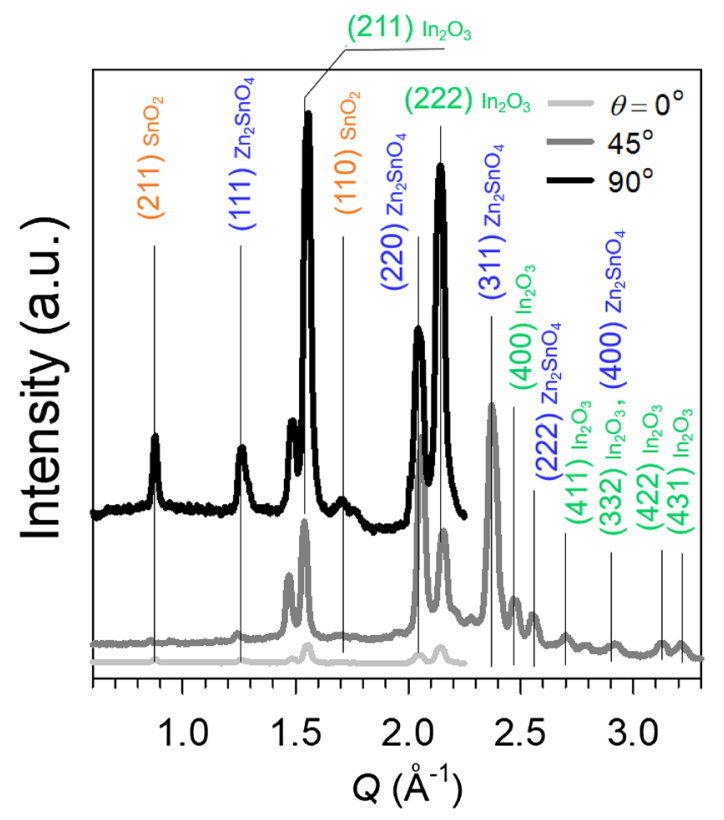

Figure 5. $1 \mathrm{D}$ GIXD patterns of the 50 -nm-thick IZTO film (annealed at $700{ }^{\circ} \mathrm{C}$ for $4 \mathrm{~h}$ ) extracted along a tilting angle $(\theta)=0,45$, and $90^{\circ}$ from the corresponding $2 \mathrm{D}$ GIXD pattern.

$\mathrm{Sn}^{4+}$ cation. Likewise, the extended solubility of In in the spinel phase can be explained by the opposite of bixbyite co-substitution; that is, two $\mathrm{In}^{3+}$ cations are substituted for one $\mathrm{Zn}^{2+}$ and one $\mathrm{Sn}^{4+}$ site. The 50 -nm-thick IZTO film revealed $d$-spacings of 4.12 and $5.05 \AA$, and the associated crystalline planes were indexed as (211) of bixbyite $\mathrm{In}_{(2-2 \mathrm{x})} \mathrm{Zn}_{\mathrm{x}} \mathrm{Sn}_{\mathrm{x}} \mathrm{O}_{3}$ and (111) of spinel $\mathrm{Zn}_{(2-\mathrm{y})} \mathrm{Sn}_{(1-\mathrm{y})} \mathrm{In}_{2 \mathrm{y}} \mathrm{O}_{4}$ crystallites, respectively (also see Figure S13). Based on the three phase identification of $\mathrm{SnO}_{2}$, a bixbyite solid solution $\operatorname{In}_{(2-2 \mathrm{x})} \mathrm{Zn}_{\mathrm{x}} \mathrm{Sn}_{\mathrm{x}} \mathrm{O}_{3}(\mathrm{x} \approx 0.4)$ and a spinel solid solution $\mathrm{Zn}_{(2-\mathrm{y})} \mathrm{Sn}_{(1-\mathrm{y})} \mathrm{In}_{2 \mathrm{y}} \mathrm{O}_{4}(\mathrm{y} \approx 0.2)$, their corresponding mole fractions in the $700{ }^{\circ} \mathrm{C}$-annealed IZTO film were estimated to be $0.20,0.20$ and 0.60 , respectively, using the lever rule principle in the sub-solid ternary phase diagram. The highest fraction $(60 \%)$ of spinel solid-solution is consistent with its dominant integrated diffraction peak area in 1D and 2D-GIXD analysis. The average grain size in the vertical direction for the crystalline IZTO films was calculated from the full-width-at-half-maximum (FWHM) using Scherrer's formula $(D=k \lambda / \beta \cos \theta$, where $D$ is an average grain size along the vertical direction, $k$ is a Scherrer constant $(\sim 0.9)$, $\lambda$ is the wavelength of the incident X-rays (1.54056 $\AA$ ), $\beta$ is the FWHM of the given reflection, and $\theta$ is the diffraction angle) (Table S3).

The mass densities of the IZTO films were calculated by X-ray reflectivity (XRR) analysis. Figure 7 shows the XRR data for the (a) 19-nm-thick IZTO films on $\mathrm{SiO}_{2} / \mathrm{Si}$ substrates annealed at 350 and $700{ }^{\circ} \mathrm{C}$ and (b) $700{ }^{\circ} \mathrm{C}$-annealed IZTO films with different thicknesses of $10,19,30$, and $50 \mathrm{~nm}$. The critical angle of the total reflection for the 19 -nm-thick IZTO film annealed at $700{ }^{\circ} \mathrm{C}$, which is proportional to the electron density for the given film, was larger than that for the same IZTO film annealed at $350^{\circ} \mathrm{C}$, indicating that the mass densification occurs during the crystallization at the elevated $T_{A}$ of $700{ }^{\circ} \mathrm{C}$. The mass densities $\left(\rho_{\text {mass }}\right)$ of 19 -nm-thick IZTO films at 350 and $700{ }^{\circ} \mathrm{C}$ were 6.63 and $6.92 \mathrm{~g} / \mathrm{cm}^{3}$, respectively, summarized in Table 1 . The effect of film thickness on the $\rho_{\text {mass }}$ values for the $700{ }^{\circ} \mathrm{C}$-annealed IZTO films was rather weak as shown in Fig. $7 \mathrm{~b}$ and Table 1.

Electrical performance of IZTO-based FETs. Figure 8 shows typical $I_{\mathrm{DS}}-V_{\mathrm{GS}}$ transfer characteristics of the $700{ }^{\circ} \mathrm{C}$-annealed IZTO FETs with different semiconducting film thicknesses ranging from 5 to $50 \mathrm{~nm}$. All the electrical properties are summarized in Table 2 . The device with a 5-nm-thick $a$-IZTO channel annealed for $1 \mathrm{~h}$ yielded a reasonable $\mu_{\mathrm{FE}}$ value of $16.6 \mathrm{~cm}^{2} \mathrm{~V}^{-1} \mathrm{~s}^{-1}$, a $V_{\mathrm{TH}}$ of $0.33 \mathrm{~V}$ and an $I_{\mathrm{ON} / \mathrm{OFF}}$ ratio of $10^{8}$. The device performance did not vary much with the annealing time, in which times from 1 to $4 \mathrm{~h}$ resulted in $\mu_{F E}$ values of $15.8-16.8 \mathrm{~cm}^{2} \mathrm{~V}^{-1} \mathrm{~s}^{-1}$ and $V_{\mathrm{TH}}$ values of $0.13-0.33$. A similar trend was observed for other thick IZTO FETs (also see Figure S14 and Table S4), so the annealing time effect will not be discussed hereafter. Interestingly, 10-nm-thick IZTO films with partially crystalline structures showed relatively improved $\mu_{\mathrm{FE}}$ values of 22.4-24.2 $\mathrm{cm}^{2} \mathrm{~V}^{-1} \mathrm{~s}^{-1}$ in FETs, as well as $V_{\mathrm{TH}}$ values of $0.63-1.00 \mathrm{~V}$ and an $I_{\mathrm{ON} / \mathrm{OFF}}$ of $\sim 10^{8}$. Among the polycrystalline IZTO films with percolated spherulites, the thinnest 19-nm-thick film-based FETs showed $\mu_{\mathrm{FE}}$ values of 39.2-39.7 $\mathrm{cm}^{2} \mathrm{~V}^{-1} \mathrm{~s}^{-1}$, which were 2.4 times greater than those of $a$-IZTO film FETs, resulting from the improved lattice ordering induced during the high temperature crystallization. The lattice ordering allows individual electron waves to be transported along the semiconducting film without energy loss, known as the "coherent scatting mechanism". However, uncontrolled crystal nucleation and growth carries the risk of forming adverse defects such as lattice-mismatched grain boundaries $(G B)$, which may act as undesirable trap sites causing the stretchout of the sub-threshold drain current region in FETs. Therefore, this trade-off relationship between carrier mobility and trap density should be carefully studied to fully understand the crystallization process.

The $S S$ value of a given FET device is a fingerprint of the total density of traps, including the fast bulk $\left(N_{T}\right)$ and semiconductor-insulator trap $\left(D_{i t}\right)$, as follows ${ }^{55}$ : 

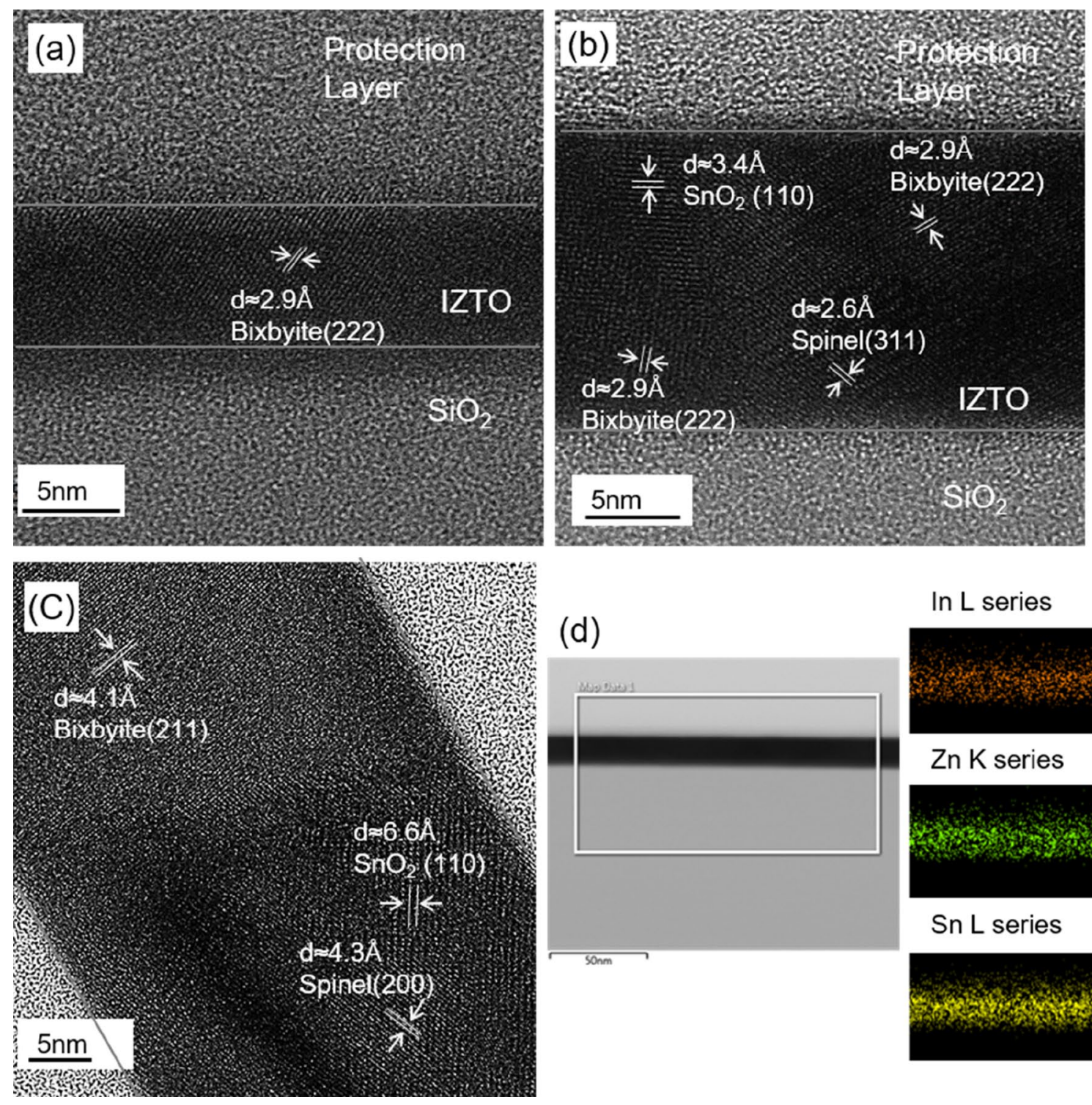

(d)

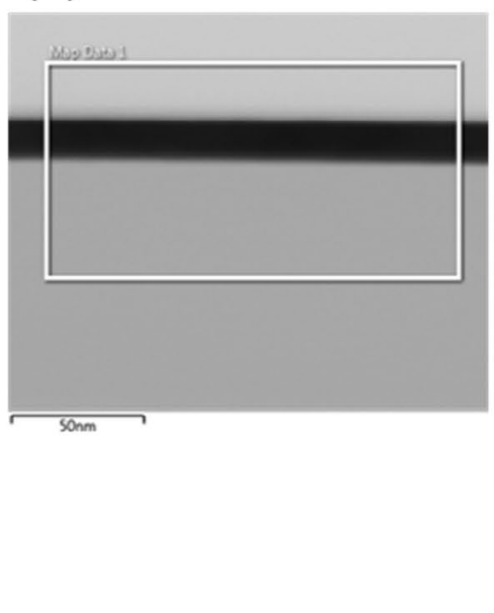

In L series

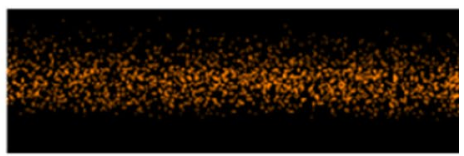

Zn K series

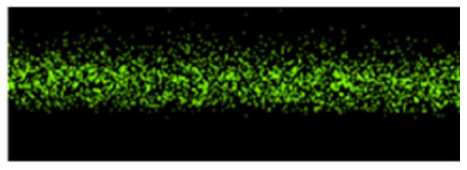

Sn L series

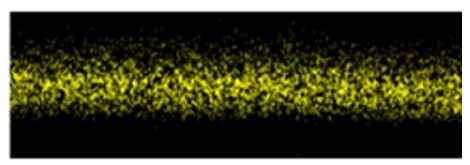

Figure 6. (a-c) Cross-sectional TEM images of 10, 19 and 50-nm-thick IZTO films. (d) Elemental mapping of 19-nm-thick IZTO film.
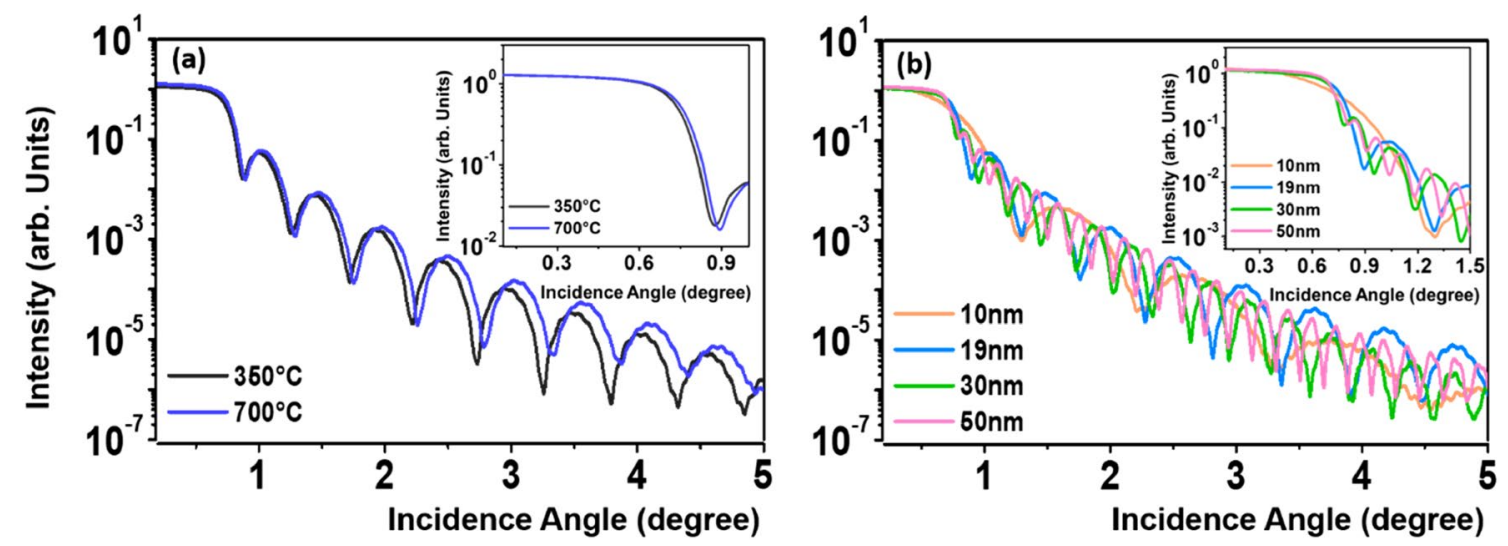

Figure 7. Measured XRR data for the (a) 19-nm-thick IZTO films on $\mathrm{SiO}_{2} / \mathrm{Si}$ substrates annealed at 350 and $700{ }^{\circ} \mathrm{C}$ and (b) $700{ }^{\circ} \mathrm{C}$-annealed IZTO films with different thicknesses of $10,19,30$, and $50 \mathrm{~nm}$. 


\begin{tabular}{|c|c|c|c|c|c|}
\hline Sample conditions & 19-nm-thick $350^{\circ} \mathrm{C}$ & 10 -nm-thick $700^{\circ} \mathrm{C}$ & 19-nm-thick $700^{\circ} \mathrm{C}$ & 30-nm-thick $700^{\circ} \mathrm{C}$ & 50-nm-thick $700^{\circ} \mathrm{C}$ \\
\hline$\rho_{\text {mass }}\left(\mathrm{g} / \mathrm{cm}^{3}\right)$ & 6.63 & 6.90 & 6.92 & 6.94 & 6.95 \\
\hline
\end{tabular}

Table 1. Variations in mass density $\left(\rho_{\text {mass }}\right.$ ) of the IZTO films of different thicknesses annealed at different $T_{A S}$.
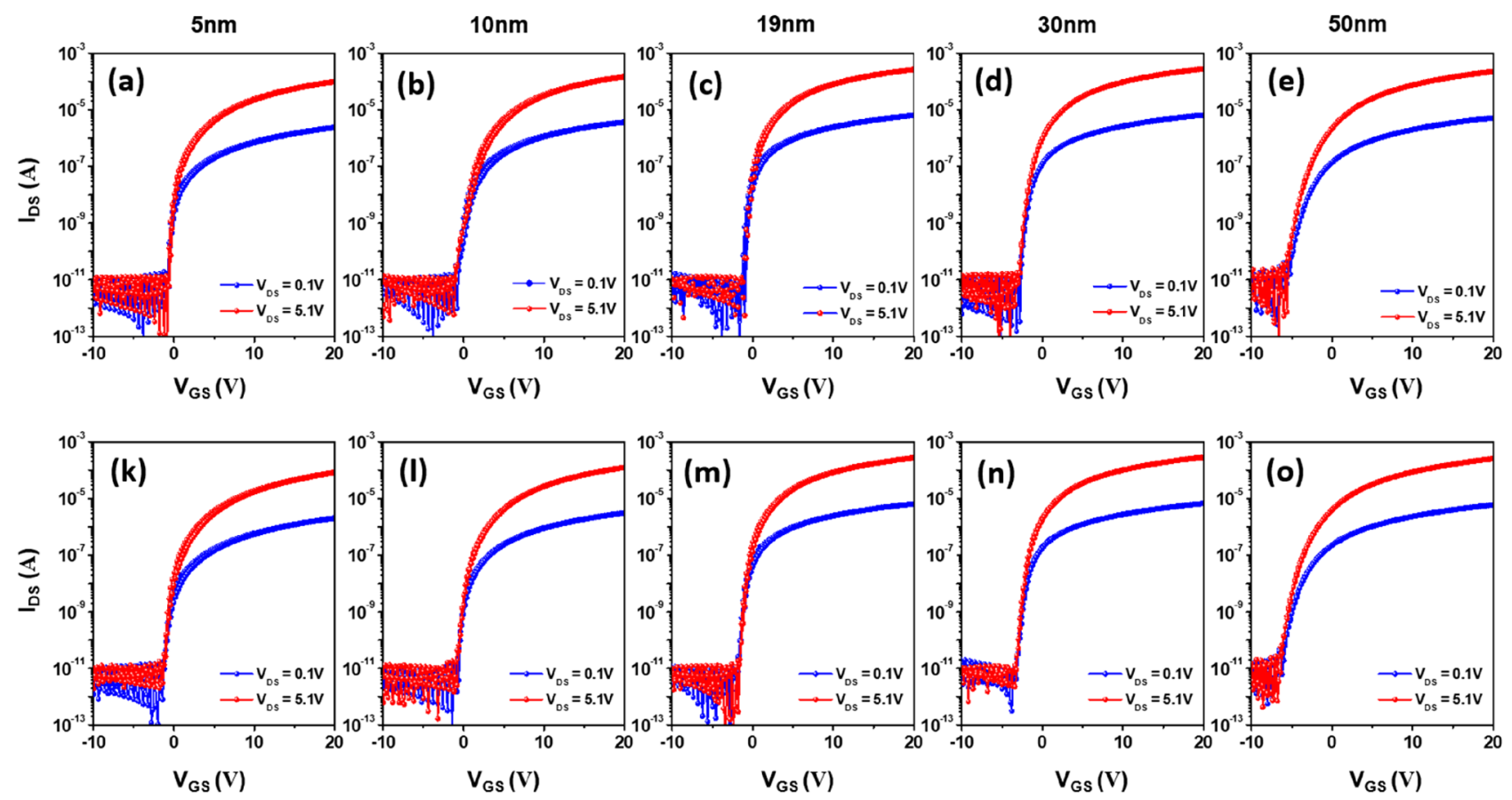

Figure 8. $I_{D S}-V_{G S}$ transfer curves of FETs including IZTO films of different thickness after annealing at $700{ }^{\circ} \mathrm{C}$ for $(\mathbf{a}-\mathbf{e}) 1$ and $(\mathbf{f}-\mathbf{j}) 4 \mathrm{~h}:(\mathbf{a}, \mathbf{f}) 5,(\mathbf{b}, \mathbf{g}) 10,(\mathbf{c}, \mathbf{h}) 19,(\mathbf{d}, \mathbf{i}) 30$, and $(\mathbf{e}, \mathbf{j}) 50 \mathrm{~nm}$.

\begin{tabular}{|c|c|c|c|c|c|c|c|}
\hline IZTO thickness & Annealing time & $\mu_{\mathrm{FE}}\left(\mathrm{cm}^{2} \mathrm{~V}^{-1} \mathrm{~s}^{-1}\right)$ & $S S\left(\mathrm{~V}\right.$ decade $\left.^{-1}\right)$ & $V_{\mathrm{TH}}(\mathbf{V})$ & $I_{\text {ON/OFF }}$ & $\begin{array}{l}D_{\mathrm{it}, \max } \\
\left(\mathrm{cm}^{-2} \mathrm{eV}^{-1}\right)\end{array}$ & $\begin{array}{l}N_{\mathrm{T}, \max } \\
\left(\mathrm{cm}^{-3} \mathrm{eV}^{-1}\right)\end{array}$ \\
\hline \multirow{2}{*}{$5 \mathrm{~nm}$} & 1 & $16.6 \pm 1.7$ & $0.50 \pm 0.03$ & $0.3 \pm 0.2$ & $9.75 \times 10^{7}$ & $1.8 \times 10^{12}$ & $3.7 \times 10^{18}$ \\
\hline & 4 & $15.8 \pm 1.8$ & $0.53 \pm 0.04$ & $0.1 \pm 0.2$ & $9.34 \times 10^{7}$ & $1.9 \times 10^{12}$ & $3.9 \times 10^{18}$ \\
\hline \multirow{2}{*}{$10 \mathrm{~nm}$} & 1 & $24.2 \pm 1.0$ & $0.59 \pm 0.09$ & $1.0 \pm 0.2$ & $4.00 \times 10^{8}$ & $2.2 \times 10^{12}$ & $2.2 \times 10^{18}$ \\
\hline & 4 & $22.4 \pm 1.5$ & $0.55 \pm 0.08$ & $0.6 \pm 0.3$ & $4.04 \times 10^{8}$ & $2.0 \times 10^{12}$ & $2.0 \times 10^{18}$ \\
\hline \multirow{2}{*}{$19 \mathrm{~nm}$} & 1 & $39.7 \pm 2.1$ & $0.26 \pm 0.06$ & $-0.2 \pm 0.4$ & $9.70 \times 10^{8}$ & $9.5 \times 10^{11}$ & $5.0 \times 10^{17}$ \\
\hline & 4 & $39.7 \pm 2.4$ & $0.27 \pm 0.07$ & $-0.7 \pm 0.4$ & $9.32 \times 10^{8}$ & $9.9 \times 10^{11}$ & $5.2 \times 10^{17}$ \\
\hline \multirow{2}{*}{$30 \mathrm{~nm}$} & 1 & $39.7 \pm 3.0$ & $0.46 \pm 0.09$ & $-1.3 \pm 1.5$ & $9.24 \times 10^{8}$ & $1.7 \times 10^{12}$ & $5.6 \times 10^{17}$ \\
\hline & 4 & $39.9 \pm 3.4$ & $0.42 \pm 0.10$ & $-2.1 \pm 1.4$ & $9.43 \times 10^{9}$ & $1.5 \times 10^{12}$ & $5.1 \times 10^{17}$ \\
\hline \multirow{2}{*}{$50 \mathrm{~nm}$} & 1 & $34.9 \pm 2.0$ & $0.97 \pm 0.12$ & $-4.0 \pm 2.3$ & $9.75 \times 10^{8}$ & $3.6 \times 10^{12}$ & $7.1 \times 10^{17}$ \\
\hline & 4 & $36.5 \pm 2.2$ & $0.97 \pm 0.13$ & $-4.2 \pm 2.2$ & $9.86 \times 10^{8}$ & $3.6 \times 10^{12}$ & $7.1 \times 10^{17}$ \\
\hline
\end{tabular}

Table 2. Typical electrical parameters of the FETs including IZTO films of different thickness annealed at $700{ }^{\circ} \mathrm{C}$ for 1 and $4 \mathrm{~h}$.

$$
S S=\frac{q k_{B} T\left(N_{T} t_{c h}+D_{i t}\right)}{C_{i} \log (e)}
$$

Here $\mathrm{q}$ is the electron charge, $k_{B}$ is Boltzmann's constant, $T$ is the absolute temperature, and $t_{c h}$ is the channel layer thickness. Note that $N_{T}$ and $D_{i t}$ values were calculated after the other parameter was set to zero, because these values corresponded to the maximum trap density existing in the system. It was found that the 5-nmthick a-IZTO channel had $N_{T}$ and $D_{i t}$ values of $3.66 \times 10^{18} \mathrm{eV}^{-1} \mathrm{~cm}^{-3}$ and $18.3 \times 10^{11} \mathrm{eV}^{-1} \mathrm{~cm}^{-2}$, respectively. The partially-crystalline film (with $10 \mathrm{~nm}$ thickness) showed similar values: $N_{T}=2.16 \times 10^{18} \mathrm{eV}^{-1} \mathrm{~cm}^{-3}$ and $D_{i t}=21.6 \times 10^{11} \mathrm{eV}^{-1} \mathrm{~cm}^{-2}$. As expected, the 19-nm-thick films with fully interconnected crystallites showed the lowest $N_{T}$ and $D_{i t}$ values of $0.50 \times 10^{18} \mathrm{eV}^{-1} \mathrm{~cm}^{-3}$ and $9.51 \times 10^{11} \mathrm{eV}^{-1} \mathrm{~cm}^{-2}$, suggesting that the improved lattice packing of the large $2 \mathrm{D}$ spherulites can compensate for the slow charge-carrier transport behavior expected at GB sites. The smaller $N_{T}$ value for the crystallized IZTO device can be understood by considering the following fact. The gap states in amorphous or weakly crystallized IZTO semiconductors come from the lattice disorder or 
under-saturated bonds $\left(V_{O}\right.$ or $V_{M}$ ), which are responsible for the larger $N_{T}$ value of their FETs. These completely disappear for the fully crystallized IZTO device. Instead, GB-related trap states are created in the forbidden gap of crystalline IZTO, which is observed in the crystalline FETs. Obviously, this indicates that the effective density of the GB-related trap states in crystallize IZTO is smaller than that of the disordered or under-statured bond induced gap states in the amorphous and partially crystalline IZTO films.

The other promising feature of transistors with the 19-nm-thick IZTO channel layer is the improved switching modulation capability, i.e., $I_{O N / O F F}$ value of $9.7 \times 10^{8}$, which was greater than those $\left(1.0-4.0 \times 10^{8}\right)$ of amorphous and partially-crystalline IZTO-based FETs. This result suggests that the $G B$ defects do not cause an adverse leakage current. It is known that the existence of $G B$ defects in the poly-Si FETs is responsible for the notorious increase in leakage current under an off-state biasing condition ${ }^{56,57}$. Some leakage current phenomena such as band-to-band tunneling, thermal/field emission, and impact ionization in the depletion region in these transistors are accelerated by the existence of $G B$ traps, which have mid-gap trap states in the forbidden region of the $\mathrm{Si}$ semiconductor. In contrast, the excellent off-state current value in the polycrystalline IZTO transistor is related to its wide bandgap nature $(>3.0 \mathrm{eV})$, which is much larger than that $(\sim 1.1 \mathrm{eV})$ of Si. Thus, the energy levels of $G B$ defects become deeper in the forbidden band of IZTO semiconductors, making these deeper levels inaccessible by the gate voltage induced Fermi-level sweep. Therefore, the polycrystalline IZTO provides enhanced $\mu_{F E}$, lower $S S$, and excellent $I_{O N / O F F}$ switching capability in the resulting FETs as compared to their polycrystalline $S i$ counterparts. However, $V_{T H}$ values for the FETs with a thicker IZTO channel layer $(\geq 30 \mathrm{~nm})$ were shifted in the negative direction (i.e. depletion mode), although high $\mu_{F E}$ values of 35.0-39.7 $\mathrm{cm}^{2} \mathrm{~V}^{-1} \mathrm{~s}^{-1}$ were achieved, comparable to that of the 19-nm-thick film. The $V_{T H}$ values for all the polycrystalline IZTO-based FETs with 19, 30 and $50 \mathrm{~nm}$-thick IZTO channel layers were $-0.21 \pm 0.35$ (for $19 \mathrm{~nm}$ ), $-1.57 \pm 1.45$ (for $30 \mathrm{~nm}$ ), and $-3.97 \pm 2.30 \mathrm{~V}$ (for $50 \mathrm{~nm}$ ), respectively (see Table 2). The negative shift in $V_{T H}$ values for the n-channel FETs is related to an increase in the $N_{e}$ of the polycrystalline IZTO films. In fully depleted thin-film transistors, $V_{T H}$ values can be represented by Eq. $(2)^{23,58}$ :

$$
V_{T H}=V_{o}-\frac{q N_{e} t_{c h}}{C_{i}}-\frac{q N_{e} t_{c h}^{2}}{2 \varepsilon_{o} \varepsilon_{r}}
$$

where $V_{0}$ is the non-ideality related constant, and $\varepsilon_{o}$ and $\varepsilon_{r}$ are the vacuum permittivity and relative dielectric constant of crystalline IZTO semiconductor, respectively. Non-linear fit between $t_{c h}$ and $V_{T H}$ for the polycrystalline IZTO film-based FETs gave an $N_{e}$ value of approximately $2.4 \times 10^{17} \mathrm{~cm}^{-3}$ for the 10 to $50 \mathrm{~nm}$ IZTO films with polycrystalline structures, which is comparable to those $\left(2.4( \pm 0.25) \times 10^{17} \mathrm{~cm}^{-3}\right)$ from Hall effect measurements. This result strongly suggests that the turn-voltage $\left(\right.$ or $V_{T H}$ ) value negatively shifted as the $t_{c h}$ value increased, as similarly reported in the $a$-IGZO transistor system ${ }^{23}$. It is also noted that $N_{T}$ values of the 30 - and 50 -nm-thick IZTO FETs were $5.1-5.6 \times 10^{17}$ and $7.1 \times 10^{17} \mathrm{eV}^{-1} \mathrm{~cm}^{-3}$, respectively, slightly higher than that of the $19-\mathrm{nm}$-thich IZTO devices, although their $I_{O N / O F F}$ values were still high enough at 9.2-9.8 $\times 10^{8}$. This result is mainly related to the diverse crystal orientation in the thicker films, where radially-grown $3 \mathrm{D}$ crystallites could be formed, and most 2D-shaped spherulites grew in a very confined thin layer (see Figs. 3 and 4). The co-existence of differently shaped and oriented crystallites can increase the GB-related trap sites, specifically, with an increase in channel thickness. It should be noted that the similar thickness dependent deterioration in terms of trap density is reported for the CAAC-IGZO TFTs ${ }^{59}$. It underpins the importance of microstructure control in the polycrystalline IZTO channel layer for use in FETs. The control of preferential orientation and single spinel phase via cation composition, thermal annealing and atmosphere etc.are expected to further reduce the bulk trap density and improve the switching properties of the resulting IZTO TFTs.

Figure 9 shows the box plot of $\mu_{F E}$ and $V_{T H}$ values for the FETs with 5,10, 19, 30 and 50-nm-thick IZTO channel layers. The standard deviation of $\mu_{F E}$ values for the IZTO FETs at $T_{A}=700{ }^{\circ} \mathrm{C}$ was rather independent of the $t_{c h}$ (Fig. 9a). In contrast, the non-uniformity for the IZTO FETs at $T_{A}=700{ }^{\circ} \mathrm{C}$ in terms of $V_{T H}$ value became worse with increasing $t_{c h}(\geq 30 \mathrm{~nm})$, whereas a comparable spread of $V_{T H}$ values was observed for the FETs with a $t_{c h} \leq 19 \mathrm{~nm}$. To obtain insight into the reason for the $t_{c h}(\geq 30 \mathrm{~nm})$-dependent $V_{T H}$ non-uniformity, these statistical data were compared to those for the $a$-IZTO FETs at $T_{A}=350^{\circ} \mathrm{C}$. For the amorphous phase, there was no strong dependence of $t_{c h}$ on the spread of $V_{T H}$ value. Therefore, the negative impact of increasing $t_{c h}(\geq 30 \mathrm{~nm}) \mathrm{on} V_{T H}$ distribution should be attributed to the diverse crystal orientation in the thicker film as previously mentioned. This indicates that the thickness of polycrystalline IZTO films ( $\sim 19 \mathrm{~nm}$ in this study) should be carefully chosen.

The gate bias stress instability, which is a critical figure-of-merit for integrated circuitry applications, was examined for the given set of IZTO FETs. Figure 10 shows variations in the $I_{D S}-V_{G S}$ transfer characteristics of the IZTO FETs under a positive gate bias stress (PBS) as a function of the stress time up to $3600 \mathrm{~s}$. The devices were stressed under a gate bias of $\left(V_{T H}+20\right) \mathrm{V}$ and a drain bias of $5.1 \mathrm{~V}$. The device with an $a$-IZTO channel layer at $T_{A}=350{ }^{\circ} \mathrm{C}\left(t_{c h}=19 \mathrm{~nm}\right.$, annealing time of $\left.1 \mathrm{~h}\right)$ was tested for comparison, as shown in Fig. 10a. The $\Delta V_{T H}$ value for the $a$-IZTO device was $4.4 \mathrm{~V}$ after the PBS duration. The FETs with an amorphous 5-nm-thick IZTO channel layer at $T_{A}=700^{\circ} \mathrm{C}$ suffered from a huge positive $V_{T H}$ shift $\left(\Delta V_{T H}=+12.2 \mathrm{~V}\right)$ after the identical PBS duration (Fig. 10b). This excessive deterioration is related to the fact that it showed the largest $N_{T}$, as previously mentioned. The adverse creation of $N_{T}$ is observed when the oxide channel thickness for FETs was ultrathin $(\leq 5 \mathrm{~nm})$ due to the surface effects ${ }^{60}$. In addition, the PBS-induced enhanced absorption of oxygen gas due to the unencapsulated nature of the device can aggravate the $V_{T H}$ shift. In the case of thinner channel devices where the screening length is larger than the channel thickness, the newly adsorbed oxygen source on the IZTO can act as an acceptor-like trap site, leading to the huge positive $V_{T H}$ shift under PBS $^{22,61}$. As the channel thickness increased, the PBS stability of the FETs improved. The $V_{T H}$ shifts for FETs with channel thicknesses of 19, 30, and $50 \mathrm{~nm}$ were reduced to $+1.52,+0.37$ and $+0.23 \mathrm{~V}$, respectively, as shown in Fig. 10d,e and f. These values were smaller than that $(+4.4 \mathrm{~V})$ of FETs with an $a$-IZTO channel layer at $T_{A}=350^{\circ} \mathrm{C}$. This superior PBS stability 

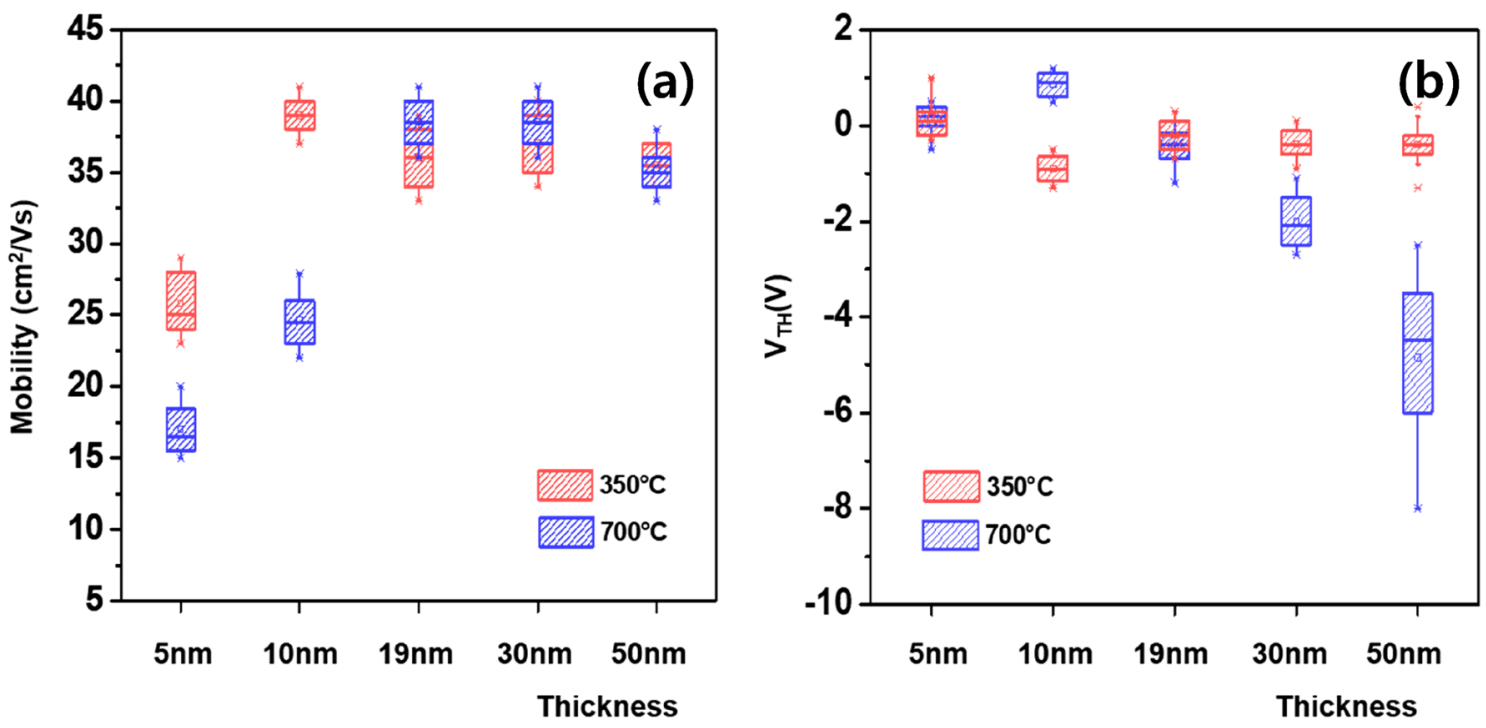

Figure 9. Box plot of the $\mu_{F E}$ and $V_{T H}$ values for the FETs with 19, 30 and 50-nm-thick IZTO channel layers. The average and standard deviation for the $\mu_{F E}$ and $V_{T H}$ values were obtained IZTO FETs with different channel thicknesses at $T_{A}=350{ }^{\circ} \mathrm{C}$ are shown in Figure S15 and Table S5.

should be attributed to the crystallization effect. Bi-stable centers such as the bond length/angle spread, undersaturated coordination, and dangling bonds in $a$-IZTO substance are eliminated as a result of lattice ordering, which results in strong immunity against external PBS. Similar behavior was also observed for the NBS-induced instabilities of the given set of IZTO FETs (Fig. 11). The devices were stressed under a gate bias of $\left(V_{T H}-20\right) \mathrm{V}$ and a drain bias of $5.1 \mathrm{~V}$. The control $a$-IZTO FETs at $T_{A}=350{ }^{\circ} \mathrm{C}$ showed a $\Delta V_{T H}$ of $5.90 \mathrm{~V}$ after NBS duration (Fig. 11a). The NBS-induced $\Delta V_{T H}$ values for devices with 5 and 10 -nm-thick IZTO at $T_{A}=700{ }^{\circ} \mathrm{C}$ increased to -14.8 and $-9.5 \mathrm{~V}$, respectively (Fig. $11 \mathrm{~b}, \mathrm{c}$ ). The smallest $\Delta V_{T H}$ value was achieved for the FETs with a $19-\mathrm{nm}$ thick fully crystallized channel layer at $T_{A}=700^{\circ} \mathrm{C}$ (see Fig. $11 \mathrm{~d}$ ).

Carrier condition mechanism. Temperature dependent Hall measurements were conducted to further study the intrinsic electrical properties of crystalline IZTO. As shown in Fig. 8, the crystalline IZTO possesses superior electrical properties compared to amorphous IZTO. The activation energy $\left(E_{a}\right)$ of the carrier density in IZTO films was extracted from the relation of $n_{e}=N_{0} \exp \left(-E_{a} / k T\right)$. As seen in Fig. 12a, a large $E_{a}$ of $\sim 0.31 \mathrm{eV}$ was confirmed for crystalline IZTO, whereas very small $E_{a}$ values of $0.027 \mathrm{eV}$ and $0.11 \mathrm{eV}$ were obtained for the $a$-IZTO and $a$-IGZO, respectively. The hydrogen in amorphous transparent oxide semiconductors acts as a shallow donor. Certainly, the hydrogen in the crystallized IZTO substance can form a deep donor responsible for the ionization energy of $\sim 0.31 \mathrm{eV}$. However, this is unlikely to occur because the post-annealing at $700{ }^{\circ} \mathrm{C}$ is high enough to desorb all hydrogens. The modification of electronic structure through crystallization can provide an alternative rationale for the increased $E_{a}$ value. The activation energy of donor levels in semiconductors should be strongly dependent on energy levels such as the conduction band minimum level $\left(E_{C B M}\right)^{62}$. To assess the optical properties for the amorphous and crystalline IZTO films, the optical band-gap values were extracted by extrapolating the best fit line in the plot of $(\alpha h v)^{0.5}$ versus $h v$ to the $\mathrm{x}$-axis intercept for the IZTO films (Fig. 12b). The optical band gap $\left(E_{G}\right)$ increased from $2.84 \mathrm{eV}$ ( $a$-IZTO film) to $3.22 \mathrm{eV}$ due to the crystallization at $700{ }^{\circ} \mathrm{C}$, which means that either $E_{C B M}$ or $E_{V B M}$ changed by $0.35 \mathrm{eV}$. For IGZO, the transformation from the amorphous phase to the crystalline phase widens $E_{G}$ and moves $E_{C B M}$ toward the vacuum energy level ${ }^{63}$. The local structures between amorphous and crystalline IGZO phases were responsible for this difference. Less strained crystalline phase structures compared to the amorphous IGZO phase involves a smaller overlap between the metal cations s-orbitals ${ }^{64}$. Considering the similarities between IGZO and IZTO, the deep activation behavior of the crystalline IZTO film can be attributed to the $E_{G}$ widening-induced $E_{C B M}$ lifting effect. That is, the local structure such as coordination numbers should be different for the amorphous and crystalline phase. For crystalline phase, coordination number tends to increase compared to amorphous phase. Even if the similar point defect is generated, the local electrostatic charge will be different depending on the local coordinate structures. It may constitute the reason why the crystallize IZTO also possess the different $E_{A}$ with amorphous phase. On the other hand, the relatively large $E_{a}$ of donor levels is responsible for their stability against NBS and PBS as compared with $a$-IZTO.

\section{Discussion}

$\mathrm{N}$-type IZTO thin films with different thicknesses ranging from 5 to $50 \mathrm{~nm}$ were annealed at 350 and $700{ }^{\circ} \mathrm{C}$ to investigate the feasibility of using polycrystalline oxide phases in FET applications. Though the amorphous phase was obtained at $T_{A}=350{ }^{\circ} \mathrm{C}$, annealing at $T_{A}=700{ }^{\circ} \mathrm{C}$ resulted in various phases including amorphous, weakly crystalline and strongly crystalline phases depending on the film thickness. A reasonably high carrier mobility $\left(35.9 \mathrm{~cm}^{2} / \mathrm{Vs}\right)$ was obtained in FETs with amorphous $19-\mathrm{nm}$-thick IZTO at $T_{A}=350^{\circ} \mathrm{C}$. However, these devices 

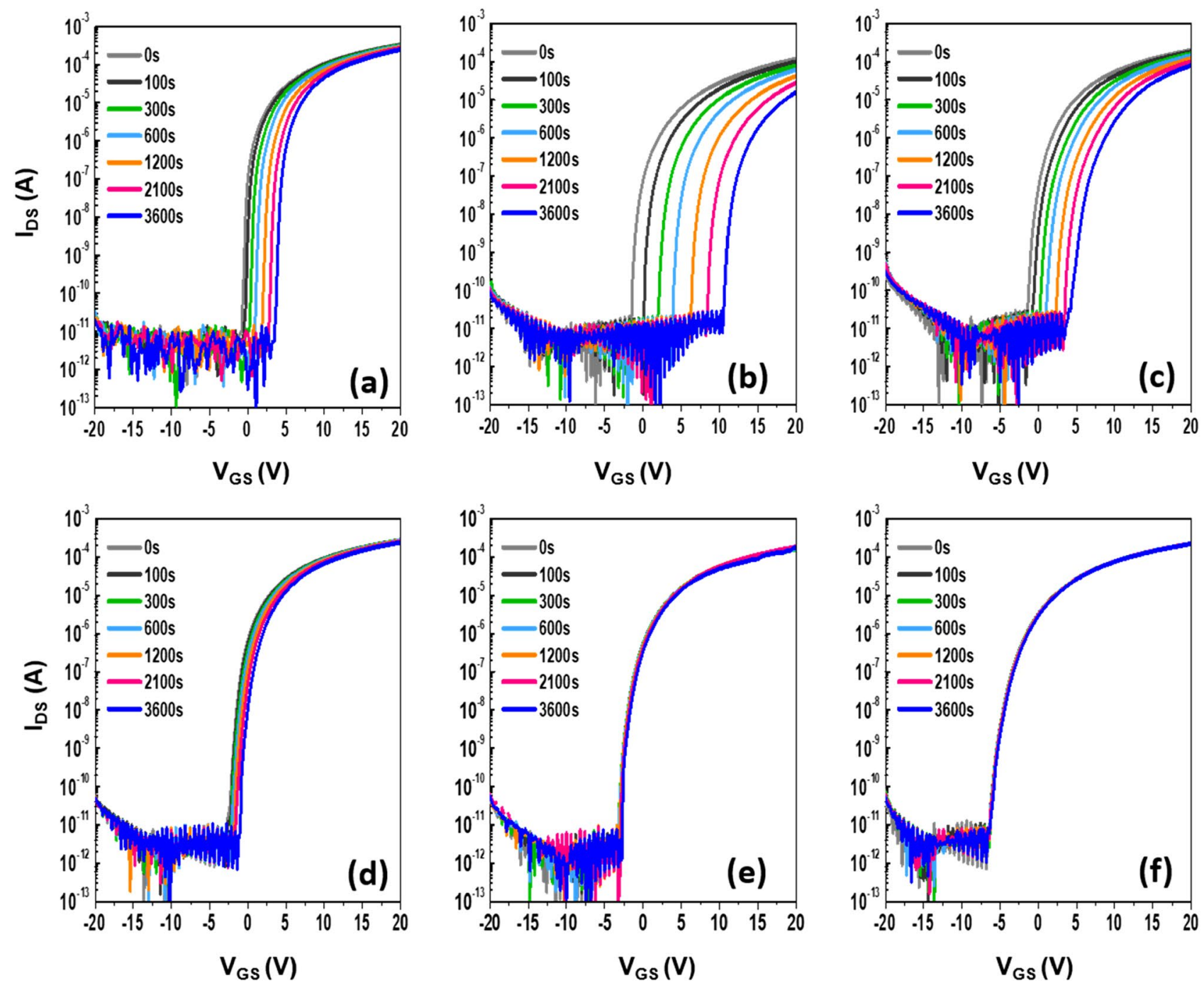

Figure 10. Evolution of transfer characteristics of IZTO TFTs prepared with (a) $19 \mathrm{~nm}$ after annealing time of $1 \mathrm{~h}$ at $350^{\circ} \mathrm{C}$ and the different thicknesses: (b) 5, (c) 10, (d) 19, (e) 30, and (f) $50 \mathrm{~nm}$ after an annealing time of $1 \mathrm{~h}$ at $700^{\circ} \mathrm{C}$ under PBS conditions. The PBS stress conditions are $V_{G S}=V_{T H}+20 \mathrm{~V}$ and $V_{D S}=5.1 \mathrm{~V}$.

fabricated at low temperature of $350^{\circ} \mathrm{C}$ suffered from non-negligible instabilities with $\Delta V_{T H}$ values under PBS and NBS of $4.4 \mathrm{~V}$ and $-5.9 \mathrm{~V}$, respectively. Complete crystallization occurred when the 19-nm-thick IZTO film was treated at the elevated annealing temperature of $700^{\circ} \mathrm{C}$, as characterized by the highly aligned bixbyite crystal and spinel structure. The resulting crystalline IZTO FETs exhibited superior performance and PBS/NBS stability compared to their counterpart $a$-IZTO FETs: the $\mu_{F E}$ value and $I_{O N / O F F}$ ratio were improved to $39.2 \mathrm{~cm}^{2} \mathrm{~V}^{-1} \mathrm{~s}^{-1}$ and $9.7 \times 10^{8}$, respectively. Also, PBS and NBS-induced $\Delta V_{T H}$ values for the crystalline IZTO FETs diminished to +1.52 and -0.13 , respectively. This was attributed to the formation of highly ordered cubic crystal structures showing the smallest $N_{T}$. However, when the channel thickness was $\geq 30 \mathrm{~nm}$, the $V_{T H}$ value for FETs with the fully crystallized IZTO at $T_{A}=700{ }^{\circ} \mathrm{C}$ shifted in the negative direction and was accompanied by $V_{T H}$ non-uniformity. The optimal thickness for the polycrystalline IZTO transistors should be carefully designed because the normallyon operation is undesirable in terms of low standby power consumption. From this investigation, we concluded that the poly-crystallization approach enables high performance IZTO transistors with excellent stability though the $G B$ defects inevitably created as a result of crystallization.

\section{Methods}

Materials and device fabrication. Amorphous IZTO thin films ranging from 5 to $50 \mathrm{~nm}$ were deposited on the $\mathrm{SiO}_{2} / \mathrm{Si}$ substrate using rf magnetron sputtering at room temperature. The 3-inch sputtering IZTO target consisted of an indium oxide $\left(\mathrm{In}_{2} \mathrm{O}_{3}\right)$, zinc oxide $(\mathrm{ZnO})$, and tin oxide $\left(\mathrm{SnO}_{2}\right)$ compound with a molar ratio of 1: 4: 4 (cation atomic percentage of In: $\mathrm{Zn}: \mathrm{Sn}$ is 20:40: 40). The $\mathrm{rf}$ power and working pressure during sputtering were fixed to $50 \mathrm{~W}$ and 3 mtorr under an Ar atmosphere, respectively. The as-deposited IZTO films were subjected to thermal treatment in an ambient atmosphere at different temperatures $\left(350,600,650\right.$, and $\left.700{ }^{\circ} \mathrm{C}\right)$ and times $(1,2$, and $4 \mathrm{~h}$ ). Device performance of semiconducting IZTO films was evaluated by fabricating the 

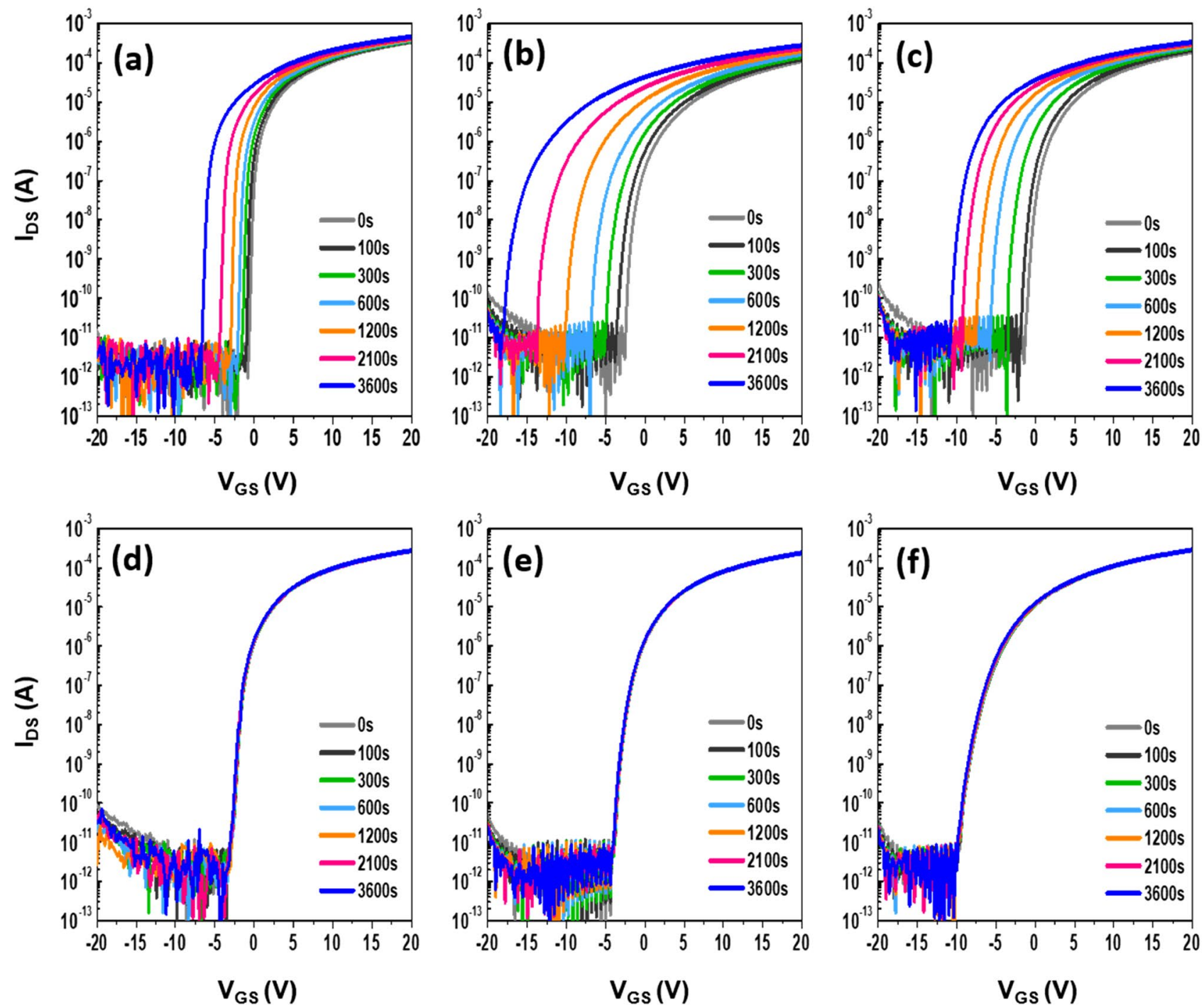

Figure 11. Evolution of transfer characteristics of IZTO TFTs prepared with (a) $19 \mathrm{~nm}$ film after annealing for $1 \mathrm{~h}$ at $350^{\circ} \mathrm{C}$ and different thicknesses: (b) 5, (c) 10, (d) 19, (e) 30, and (f) $50 \mathrm{~nm}$ after an annealing time of $1 \mathrm{~h}$ at $700{ }^{\circ} \mathrm{C}$ under NBS conditions. The NBS stress conditions are $V_{G S}=V_{T H}-20 \mathrm{~V}$ and $V_{D S}=5.1 \mathrm{~V}$.

bottom-gate thin-film transistors. A heavily doped $(<0.005 \Omega \mathrm{cm})$ Si substrate and a thermally-grown $100-\mathrm{nm}$ thick $\mathrm{SiO}_{2}$ layer served as the gate electrode and gate dielectric, respectively. After depositing the IZTO film on $\mathrm{SiO}_{2} / \mathrm{Si}$, a tin-doped indium oxide (ITO) film as a source/drain $(S / D)$ electrode was deposited using the identical sputtering system. All the active channel and $S / D$ electrode layers were patterned through a shadow mask during each deposition. The resulting FETs had a channel width $(W)$ of $1000 \mu \mathrm{m}$ and a length $(L)$ of $300 \mu \mathrm{m}$. Then, the fabricated FETs were subjected to thermal annealing in an ambient atmosphere at different annealing temperatures $\left(350,600,650\right.$, and $\left.700{ }^{\circ} \mathrm{C}\right)$ and times $(1,2$, and $4 \mathrm{~h})$.

Film and device characterization. The structural properties of the IZTO films were analyzed by conventional grazing-incidence X-ray diffraction (GIXD, Smart Lab, Regaku, Japan) using $\mathrm{Cu} \mathrm{Ka}$ radiation $(\lambda=1.54056 \AA)$. Also, synchrotron-based high-resolution two-dimensional (2D) GIXD measurements were performed on the IZTO films at the Pohang Accelerator Laboratory, 6D and 9A beamlines ${ }^{65}$. Each sample was mounted on a two-axis goniometer on top of an $\mathrm{x}-\mathrm{z}$ stage, and the scattering intensity was measured using a $2 \mathrm{D}$ Mar CCD detector. The physical thickness of the IZTO films was calculated from the oscillation scattering period $\left(\Delta Q_{\mathrm{z}}\right)$ of the X-ray reflectivity profiles using the following equation: $\Delta Q_{\mathrm{z}}=2 \pi / t_{\mathrm{ch}}$, where $t_{\mathrm{ch}}$ is the thickness of the IZTO films. The thickness of the IZTO films was also double-checked by spectroscopic ellipsometry (SE, ElliSE, Ellipso Technology Co.). The microstructure of the IZTO films on $\mathrm{Si} / \mathrm{SiO}_{2}$ substrates was analyzed by both field emission scanning electron microscopy (FE-SEM, Verios G4 UC, FEI Co.) and atomic force microscopy (AFM, Multimode 8, Bruker). The cross-sectional nanoscale structures for IZTO films were observed using Cs corrected transmission electron microscopy (CS-TEM, JEM 2100F, JEOL Ltd). The TEM samples were prepared using a focused ion beam-field scanning electron microscope (FIB-FESEM, Helios G4, Thermo Fisher Scientific Co.) employing a Ga liquid metal ion source at an acceleration voltage of $30 \mathrm{kV}$. The elemental depth profiles 

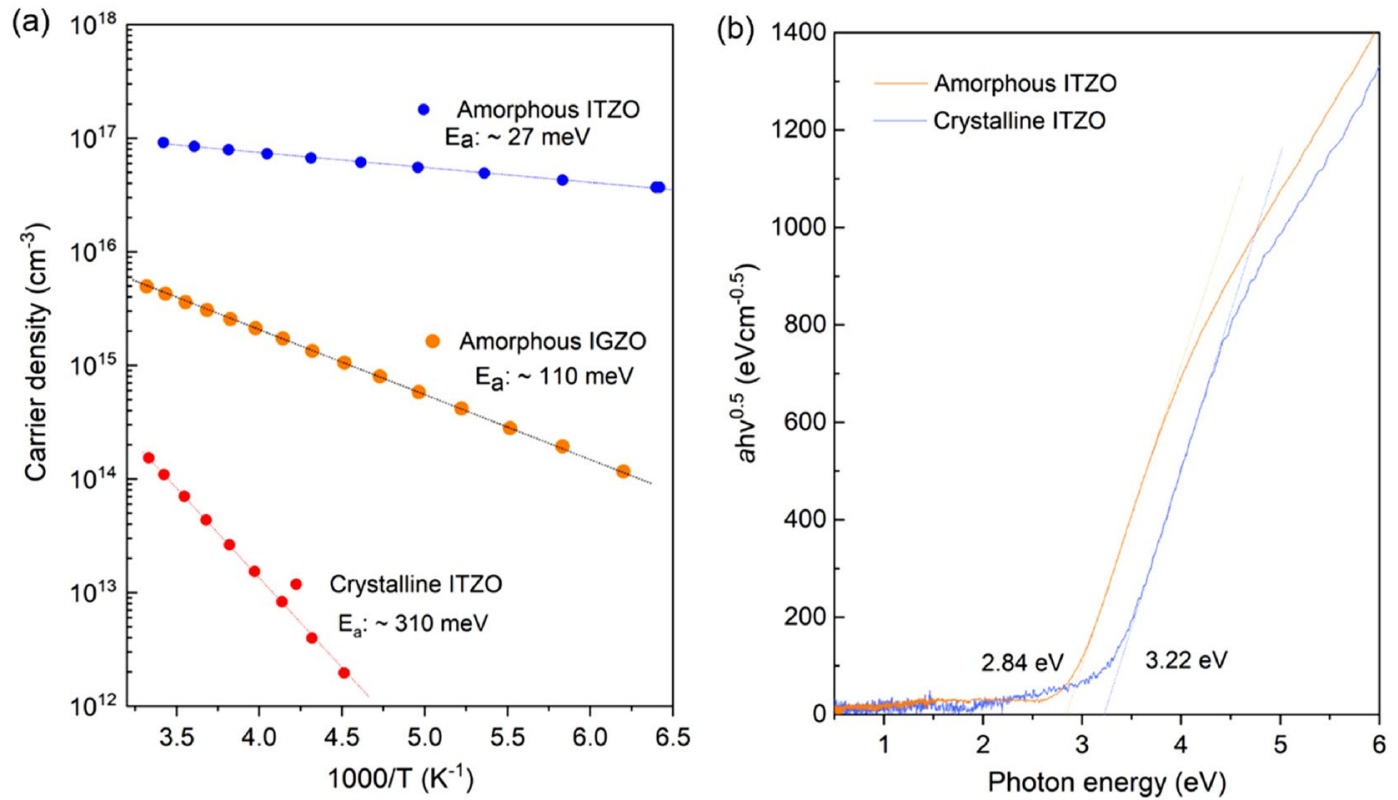

Figure 12. (a) Temperature dependent Hall measurement result of $N_{e^{*}}$ (b) Comparison of optical $E_{G S}$ between amorphous and crystalline IZTO thin films.

from the IZTO to the $\mathrm{SiO}_{2}$ were measured by the time-of-flight secondary ion mass spectrometry (TOF-SIMS, ION-TOF). The chemical composition of the IZTO films was determined by X-ray fluorescence (XRF, ZSX Primus II, Rigaku) spectroscopy, for which the atomic concentration was calibrated by proton-induced X-ray emission. The cation compositions of In: $\mathrm{Zn}$ : $\mathrm{Sn}$ in as-deposited and $350{ }^{\circ} \mathrm{C}$-annealed IZTO films were $24-25$ : 37-38: 38-39 at\%, as determined by XRF, which was double-checked by EDS analysis. The different compositions of IZTO films compared to that of the IZTO sputtering target are due to the different sputtering yields of constituent cation atoms. The cation composition of In: $\mathrm{Zn}$ : $\mathrm{Sn}$ in the IZTO films annealed at $700{ }^{\circ} \mathrm{C}$ with the different physical thicknesses of 10, 19, and $50 \mathrm{~nm}$ were 23-24: 35-37: 40-41 at\%. The slight lower fraction (35-37 at $\%$ ) of $\mathrm{Zn}$ in the $700{ }^{\circ} \mathrm{C}$-annealed IZTO films suggests that it was lost during high temperature annealing due to its volatile nature. Optical band gaps of IZTO films were estimated from optical absorption spectra (UH4150, Hitachi). The Hall mobility $\left(\mu_{\text {Hall }}\right)$ and free carrier concentration $\left(N_{e}\right)$ of the IZTO films were evaluated from Hall effect measurements using the van der Pauw configuration. Temperature dependent Hall measurements were carried out using an AC field Hall effect measurement apparatus (ResiTest8400, Toyo Corp). The 19-nm-thick $a$-IZTO and $c$-IZTO films were deposited on $\mathrm{Si} / \mathrm{SiO}_{2}$ substrates, which was subjected to the thermal annealing at 350 and $700{ }^{\circ} \mathrm{C}$, respectively. For comparison, $a$-IGZO films annealed at $350{ }^{\circ} \mathrm{C}$ in an ambient atmosphere for $1 \mathrm{~h}$ were also characterized where the cation atomic percentage of In: Ga: Zn was 1: 1: 1. Then, the ITO electrode with $180 \mathrm{~nm}$ thickness on the IZTO and IGZO samples was sputtered through shadow mask, which was followed by the contact annealing $300^{\circ} \mathrm{C}$ for $1 \mathrm{~h}$ in an air atmosphere for Ohmic contact. Electrical characteristics of the IZTO FETs were measured at room temperature under a dark ambient condition using a Keithley 4200 analyzer. The field-effect mobility $\left(\mu_{\mathrm{FE}}\right)$ for the given FETs was calculated based on the maximum peak value at a drain voltage $\left(V_{\mathrm{DS}}\right)$ of $0.1 \mathrm{~V}$. The threshold voltage $\left(V_{\mathrm{TH}}\right)$ was determined as the gate voltage $\left(V_{\mathrm{GS}}\right)$ that induced a drain current $\left(I_{\mathrm{DS}}\right)$ of $L / W \times 10 \mathrm{nA}$ at a $V_{\mathrm{DS}}$ of $5.1 \mathrm{~V}$. The subthreshold gate swing $\left(S S=\mathrm{d} V_{\mathrm{GS}} / \mathrm{d} \log I_{\mathrm{DS}}\right)$ was extracted from the linear part of the $\log \left(I_{\mathrm{DS}}\right)-V_{\mathrm{GS}}$ plot.

Received: 13 June 2020; Accepted: 22 October 2020

Published online: 02 November 2020

\section{References}

1. Nomura, K. et al. Room-temperature fabrication of transparent flexible thin-film transistors using amorphous oxide semiconductors. Nature 432, 488-492 (2014).

2. Kamiya, T. et al. Present status of amorphous In-Ga-Zn-O thin-film transistors. Sci. Technol. Adv. Mater. 11, 044305 (2010).

3. Jang, H. J. et al. Progress of display performance: AR, VR, QLED, OLED, and TFT. J. Inf. Disp. 20, 1 (2019).

4. Fortunato, E. et al. Oxide semiconductor thin-film transistors: a review of recent. Advances Adv. Mater. 24, 2945-2986 (2012).

5. Kwon, J. Y. \& Jeong, J. K. Recent progress in high performance and reliable n-type transition metal oxide-based thin film transistors. Semicond. Sci. Technol. 30, 024002 (2015).

6. Park, J.-S. et al. Overview of electroceramic materials for oxide semiconductor thin film transistors. J. Electroceram. 32, 117-140 (2014).

7. Noh, J.-Y. et al. Cation composition effects on electronic structures of In-Sn-Zn-O amorphous semiconducting. J. Appl. Phys. 113, 183706 (2013). 
8. Song, J. H. et al. Achieving high field-effect mobility exceeding $50 \mathrm{~cm}^{2} / \mathrm{Vs}$ in In-Zn-Sn-O thin-film transistors. IEEE Electron Device Lett. 35(8), 853-855 (2014).

9. Ryu, M. K. et al. High performance thin film transistor with cosputtered amorphous Zn-In-Sn-O channel: combinatorial approach. Appl. Phys. Lett. 95, 072104 (2009).

10. Hwang, E. S. et al. $\mathrm{In}_{2} \mathrm{Ga}_{2} \mathrm{ZnO}_{7}$ oxide semiconductor based charge trap device for NAND flash memory. Nanotechnology 29, 155203 (2018).

11. Rha, S. H. et al. Vertically integrated submicron amorphous- $\mathrm{In}_{2} \mathrm{Ga}_{2} \mathrm{ZnO}_{7}$ thin film transistor using a low temperature process. Appl. Phys. Lett. 100, 203510 (2012).

12. Choi, S. et al. A novel structure for improving erase performance of vertical channel NAND flash with an indium-gallium-zincoxide channel. IEEE Trans. Electron Devices. 66, 4739-4744 (2019).

13. Ahn, M.-J. \& Cho, W.-J. Transparent multi-level-cell nonvolatile memory with dual-gate amorphous indium-gallium-zinc oxide thin-film transistors. Appl. Phys. Lett. 109, 252106 (2016).

14. Rha, S. H. et al. Double-layered vertically integrated amorphous- $\mathrm{In}_{2} \mathrm{Ga}_{2} \mathrm{ZnO}_{7}$ thin-film transistor. Appl. Phys. Lett. 103, 183503 (2013).

15. Jung, J. S. et al. The charge trapping characteristics of $\mathrm{SiN}_{4}$ and $\mathrm{Al}_{2} \mathrm{O}_{3}$ layer on amorphous-indium-gallium-zinc oxide thin films for memory application. Appl. Phys. Lett. 100, 183503 (2012).

16. Chang, S. et al. Efficient suppression of charge trapping in $\mathrm{ZnO}$-based transparent thin film transistors with novel $\mathrm{Al}_{2} \mathrm{O}_{3} / \mathrm{HfO}_{2} /$ $\mathrm{Al}_{2} \mathrm{O}_{3}$ structure. Appl. Phys. Lett. 92, 192104 (2008).

17. Na, S.-Y. \& Yoon, S.-M. Impacts of $\mathrm{HfO}_{2} / \mathrm{ZnO}$ stack-structured charge-trap layers controlled by atomic layer deposition on nonvolatile memory characteristics of In-Ga-Zn-O channel charge-trap memory thin-film transistors. IEEE J. Electron Devices Soc. 7, 453-461 (2019).

18. Wehrsohn, R. B. et al. Dangling-bond defect state creation in microcrystalline silicon thin-film transistors. Appl. Phys. Lett. 77, 750-752 (2000).

19. Karim, K. S. et al. Drain-bias dependence of threshold voltage stability of amorphous silicon TFTs. IEEE Electron Device Lett. 25, 188-190 (2004).

20. Chen, C.-Y. et al. Negative bias temperature instability in low-temperature polycrystalline silicon thin-film transistors. IEEE Trans. Electron Devices. 53, 2993-3000 (2006).

21. Son, K.-S. et al. 4inch QVGA AMOLED drive by the threshold voltage controlled amorphous $\mathrm{GIZO}\left(\mathrm{Ga}_{2} \mathrm{O}_{3}-\mathrm{In}_{2} \mathrm{O}_{3}-\mathrm{ZnO}\right) \mathrm{TFT}$. SID Symp. Dig. Tech. Pap. 39, 633-636 (2008).

22. Jeong, J. K. et al. Origin of threshold voltage instability in indium-gallium-zinc oxide thin film transistors. Appl. Phys. Lett. 93, 123508 (2008).

23. Park, J.-S. et al. Control of threshold voltage in ZnO-based oxide thin film transistors. Appl. Phys. Lett. 93, 033513 (2008).

24. Kang, Y. et al. Hydrogen bistability as the origin of photo-bias-thermal instabilities in amorphous oxide semiconductors. $A d v$. Electron. Mater. 1, 1400006 (2015).

25. Nomura, K. et al. Carrier Transport in transparent oxide semiconductor with intrinsic structural randomness probed using singlecrystalline $\mathrm{InGaO}_{3}(\mathrm{ZnO})_{5}$ films. Appl. Phys. Lett. 85, 1993 (2004).

26. Nomura, K. et al. Amorphous oxide semiconductors for high-performance flexible thin-film transistors. Jpn. J. Appl. Phys. 45, 4303-4308 (2006).

27. Ahn, B. K. et al. Origin of device performance degradation in InGaZnO thin-film transistors after crystallization. Jpn. J. Appl. Phys. 51, 015601 (2011).

28. Kim, G. H. et al. Formation mechanism of solution-processed nanocrystalline InGaZnO thin film as active channel layer in thinfilm transistor. J. Electrochem. Soc. 156, H7-H9 (2009).

29. Park, K. et al. Reliability of crystalline indium-gallium-zinc-oxide thin-film transistors under bias stress with light illumination. IEEE Trans. Electron Devices. 62, 2900-2905 (2015)

30. Shin, Y. et al. The mobility enhancement of indium gallium zinc oxide transistors via low-temperature crystalline using a tantalum catalytic layer. Sci. Rep. 71, 10885 (2017).

31. Baccarani, G. et al. Transport properties of polycrystalline silicon films. J. Appl. Phys. 49, 5565-5570 (1978).

32. Kimura, M. et al. Dependence of polycrystalline silicon thin-film transistor characteristics on the grain-boundary location. J. Appl. Phys. 89(1), 596-600 (2001).

33. Kimura, M. et al. Device simulation of carrier transport through grain boundaries in lightly doped polysilicon films and dependence on dopant density. Jpn. J. Appl. Phys. 40, 5237-5243 (2001).

34. Medvedeva, J. E. et al. Recent advances in understanding the structure and properties of amorphous oxide semiconductors. Adv. Electron. Mater. 3, 1700082 (2017).

35. Yabuta, H. et al. Microscopic structure and electrical transport property of sputtered-deposited amorphous indium-gallium-zinc oxide semiconductor films. J. Phys. Conf. Ser. 518, 012001 (2014).

36. Buchholz, D. B. et al. The structure and properties of amorphous indium oxide. Chem. Mater. 26, 5401-5411 (2014).

37. Kim, H. et al. Impact of bias stability for crystalline InZnO thin-film transistors. Appl. Phys. Lett. 10, 232104 (2017).

38. Chang, K. J. et al. Theory of hydrogen passivation of shallow-level dopants in crystalline silicon. Phys. Rev. Lett. 60, 1422-1425 (1988).

39. Bang, J. et al. Diffusion and thermal stability of hydrogen in ZnO. Appl. Phys. Lett. 92, 132109 (2008).

40. Bang, J. et al. Hydrogen anion and subgap states in amorphous In-Ga-Zn-O thin films for TFT applications. Appl. Phys. Lett. 110, 232105 (2017).

41. Hanyu, Y. et al. Hydrogen passivation of electron trap in amorphous In-Ga-Zn-O thin-film transistors. Appl. Phys. Lett. 103, 202114 (2013).

42. On, N. et al. Origin of electrical instabilities in self-aligned amorphous In-Ga-Zn-O thin-film transistors. IEEE Trans. Electron Devices 64, 4965-4973 (2017).

43. Sadananda Kumar, N. et al. Effect of annealing on the properties of zinc oxide nanofiber thin films grown by spray pyrolysis technique. Appl. Nanosci. 4, 209-216 (2014).

44. Shi, L. et al. Annealing temperature effects on photoelectrochemical performance of bismuth vanadate thin film photoelectrodes. RSC. Adv. 8, 29179 (2008).

45. Ahmed, N. M. et al. The effect of post annealing temperature on grain size of indium-tin-oxide for optical and electrical properties improvement. Res. in Phys. 13, 102159 (2019).

46. Wang, J. et al. One-pot hydrothermal synthesis of highly efficient $\mathrm{SnO}_{\mathrm{x}} / \mathrm{Zn}_{2} \mathrm{SnO}_{4}$ composite photocatalyst for the degradation of methyl orange and gaseous benzene. Appl. Catal. B: Environ. 200, 19-30 (2007).

47. Yuan, H.-L. \& Li, J.-C. Effect of annealing temperature on the growth of $\mathrm{Zn}-\mathrm{Sn}-\mathrm{O}$ nanocomposite thin films. J. Alloys Compd. 714, 114-119 (2017).

48. Nayak, A. K. et al. Biomolecule-assisted synthesis of $\mathrm{In}(\mathrm{OH})_{3}$ nanocubes and $\operatorname{In}_{2} \mathrm{O}_{3}$ nanoparticles: photocatalytic degradation of organic contaminants and CO oxidation. Nanotechnology 26, 485601 (2015).

49. Liu, D. et al. High-pressure x-ray diffraction and raman spectra study of indium oxide. J. Appl. Phys. 104, 083506 (2008).

50. Harvey, S. P. et al. Subsolidus phase relationships in the $\mathrm{ZnO}-\mathrm{In}_{2} \mathrm{O}_{3}-\mathrm{SnO}_{2}$ system. J. Am. Ceram. Soc. 91, 3683-3689 (2008).

51. Hoel, C. A. et al. Transparent conducting oxides in the $\mathrm{ZnO}-\mathrm{In}_{2} \mathrm{O}_{3}-\mathrm{SnO}_{2}$ system. Chem. Mater. 22, 3569-3579 (2010). 
52. Jantzen, T. et al. Thermodynamic assessment of oxide system $\mathrm{In}_{2} \mathrm{O}_{3}-\mathrm{SnO}_{2}-\mathrm{ZnO}$. Chim. Techno Acta. 5, 166-188 (2018).

53. Hoel, C. A. et al. Evidence for tetrahedral zinc in amorphous $\operatorname{In}_{2-2 x} \mathrm{Zn}_{\mathrm{x}} \mathrm{Sn}_{\mathrm{x}} \mathrm{O}_{3}$ (a-ZITO). Z. Anorg. Allg. Chem. 637, 885-894 (2011).

54. Hoel, C. A. et al. High-pressure synthesis and local structure of corundum-type $\operatorname{In}_{2-2 x} Z_{n} \operatorname{Sn}_{x} \mathrm{O}_{3}(x \leq 0.7)$. J. Am. Chem. Soc. 132, 16479-16487 (2010).

55. Choi, I. M. et al. Achieving high mobility and excellent stability in amorphous In-Ga-Zn-Sn-O thin-film transistors. IEEE Trans. Electron Devices 67, 1014-1020 (2020).

56. Chang, K. M. et al. Electrical characteristics of low temperature polysilicon TFT with a novel TEOS/oxynitride stack gate dielectric. IEEE Electron Device Lett. 24, 512-514 (2003).

57. Watanabe, H. Statistics of grain boundaries in polysilicon. IEEE Trans. Electron Devices. 54, 38-44 (2007).

58. Nakata, M. et al. Influence of oxide semiconductor thickness on thin-film transistor characteristics. Jpn. J. Appl. Phys. 52, 03BB04 (2013).

59. Zhang, J. et al. C-Axis oriented crystalline IGZO thin-film transistors by magnetron sputtering. J. Mater. Chem. C. 5, 2388-2396 (2015).

60. Lee, S. Y. et al. Effect of channel thickness on density of states in amorphous InGaZnO thin film transistor. Appl. Phys. Lett. 98, 122105 (2011).

61. Park, J. S. et al. Electronic transport properties of amorphous indium-gallium-zinc oxide semiconductor upon exposure to water. Appl. Phys. Lett. 92, 072104 (2008).

62. Robertson, J. Properties and doping limits of amorphous oxide semiconductors. J. Non-Cryst. Solids. 358, 2437-2442 (2012).

63. Kang, Y. et al. Nature of visible-light absorption in amorphous semiconducting oxides. APL Mater. 2, 032108 (2014).

64. Kim, J. et al. Ultra-wide bandgap amorphous oxide semiconductors for NBIS-free thin-film transistors. APL Mater. 7, 022501 (2019).

65. Gao, C. Y. et al. Spontaneous phase separation of poly(3-hexylthiophene)s with different regioregularity for a stretchable semiconducting film. Adv. Funct. Mater. 29, 1903163 (2019).

\section{Acknowledgements}

This work was supported by a research Grant from Samsung Display and National R\&D Program through the National Research Foundation of Korea (NRF) funded by Ministry of Science and ICT(2020M3F3A2A01081240). HY thanks the National Research Foundation (NRF) of Korea funded by the Korean government (2020R1A4A3079923).

\section{Author contributions}

N.O., J.H.L. and J.K.J. designed this work. H.Y., J.K. and J.K.J. wrote the main text. N.O. and B.K.K. fabricated and characterized the devices. Y.K. and H.Y. performed the AFM and GIXD analysis. E.H.K contributed to the XPS analysis. H.H. and K.J. contributed to the Hall measurement and optical characteristics. All authors discussed the results and commented on the manuscript. The project was supervised by J.K.J.

\section{Competing interests}

The authors declare no competing interests.

\section{Additional information}

Supplementary information is available for this paper at https://doi.org/10.1038/s41598-020-76046-w.

Correspondence and requests for materials should be addressed to J.K., H.Y. or J.K.J.

Reprints and permissions information is available at www.nature.com/reprints.

Publisher's note Springer Nature remains neutral with regard to jurisdictional claims in published maps and institutional affiliations.

(c) (i) Open Access This article is licensed under a Creative Commons Attribution 4.0 International License, which permits use, sharing, adaptation, distribution and reproduction in any medium or format, as long as you give appropriate credit to the original author(s) and the source, provide a link to the Creative Commons licence, and indicate if changes were made. The images or other third party material in this article are included in the article's Creative Commons licence, unless indicated otherwise in a credit line to the material. If material is not included in the article's Creative Commons licence and your intended use is not permitted by statutory regulation or exceeds the permitted use, you will need to obtain permission directly from the copyright holder. To view a copy of this licence, visit http://creativecommons.org/licenses/by/4.0/.

(c) The Author(s) 2020 